Affective Design using machine learning: A survey and its prospect of conjoining big data

Kit Yan Chan ${ }^{1}$, C.K. Kwong 2 , Ponnie Clark ${ }^{3}$, Huimin Jiang ${ }^{2}$, Chris K.Y. Fung ${ }^{2}$, Bilal Abu Salih ${ }^{3}$, Zhixin Liu ${ }^{4}$, Andy T.C. Wong ${ }^{5}$, Pratima Jain ${ }^{3}$

${ }^{1}$ School of Electrical, Computing and Mathematical Sciences, Curtin University, Western Australia, Australia (kit.chan@curtin.edu.au)

${ }^{2}$ Department of Industrial and Systems Engineering, The Hong Kong Polytechnic University, Hong Kong (c.k.kwong@polyu.edu.hk; huimin.jiang@connect.polyu.hk; chris.ky.fung@connect.polyu.hk)

${ }^{3}$ School of Information Systems, Curtin University, Western Australia, Australia (ponnie.clark@curtin.edu.au; bilal.abusalih@curtin.edu.au; pratima.jain@sstudent.curtin.edu.au)

${ }^{4}$ Institute of Electrical Engineering, Yanshan University, Qinhuangdao 066004, China (lzxauto@ysu.edu.cn)

${ }^{5}$ Department of Design, Manufacture, and Engineering Management, University of Strathclyde, United Kingdom (andy.wong@strath.ac.uk)

Number of words: 14935

Corresponding author:

Kit Yan Chan (kit.chan@curtin.edu.au)

School of Electrical, Computing and Mathematical Sciences, Curtin University, Western Australia, Australia 


\section{Affective Design using machine learning: A survey and its prospect of conjoining big data}

Customer satisfaction in purchasing new products is an important issue that needs to be addressed in today's competitive markets. Consumers not only need to be solely satisfied with the functional requirements of a product, and they are also concerned with the affective needs and aesthetic appreciation of the product. A product with good affective design excites consumer emotional feelings so as to buy the product. However, affective design often involves complex and multi-dimensional problems for modelling and maximising affective satisfaction of customers. Machine learning is commonly used to model and maximise the affective satisfaction, since it is effective in modelling nonlinear patterns when numerical data relevant to the patterns is available. This article presents a survey of commonly used machine learning approaches for affective design when two data streams namely traditional survey data and modern big data are used. A classification of machine learning technologies is first provided which is developed using traditional survey data for affective design. The limitations and advantages of each machine learning technology are also discussed and we summarize the uses of machine learning technologies for affective design. This review article is useful for those who use machine learning technologies for affective design. The limitations of using traditional survey data are then discussed which is time consuming to collect and cannot fully cover all the affective domains for product development. Nowadays, big data related to affective design can be captured from social media. The prospects and challenges in using big data are discussed so as to enhance affective design, in which very limited research has so far been attempted. This article provides guidelines for researchers who are interested in exploring big data and machine learning technologies for affective design.

Keywords: affective design, machine learning, big data, affective smart systems, social media, Kansei engineering, new product development 


\section{Introduction}

Nowadays, consumers are not only concerned with the functionality and reliability of products, and they are also concerned with product affections such as texture, shape, colour, and style which are related to the emotional feelings and impressions of the products (Zhang and Li 2005). Products need to appeal to users on an affective level in order to be successful in the market. The term affective design originated from Kurosu and Kashimura (Kurosu and Kashimura 1995) who developed two cash teller machines with each having identical functional features for making enquiring and withdrawing. One machine was equipped with attractive interfaces and the other machine with less attractive ones. The survey indicated that the attractive machine was more usable. A more recent example refers to the affective design of smart phones ( Kim and Lee 2016). Some smart phones were equipped with more attractive interfaces while others had less attractive ones. The survey showed that the attractive ones attracted more consumers, although both smartphones were developed with similar functions and specifications. Hence, the importance of affective design can be stated as: products with good affective design excite psychological feelings, improve consumer satisfaction in terms of emotional aspects and increase the willingness to purchase. Therefore, affective design becomes vital in the realm of new product development (McDonagh, Bruseberg, and Haslam 2002) as it has impact on changing users' purchasing intentions (Smith and Smith 2012).

Affective design attempts to determine the emotional relationships between consumers and products and to study the perceptual design elements which are correlated to the affective qualities of the products (Norman 2004). Unlike evaluating product functionality and usability, it is more challenging to identify and measure affective influences on products for prospective users, as affective influences are subjective and inconsistent over time. Generally, affective influences on products are obtained by questionnaire or interview based survey data with affective scores from products (Nagamachi 2010). Such survey data is imprecise, uncertain and vague, as survey questionnaires or interview questions are designed based on product engineers' experience in the affective aspects to the product and also the questionnaire scores or interview answers involve consumers' subjective opinions. In the questionnaire or interview surveys, respondents are asked to indicate their responses / assessments on 
various affective aspects of products. As their responses / assessments are always subjective and imprecise (e.g. the color is quite appealing.), it is unavoidable that the survey data contains a high degree of evaluation uncertainty. Thanks to advancements in machine learning techniques, machine learning constitutes the core of affective design using survey data. One of the purposes of this article is to review recently developed machine learning techniques for affective design. Ninety-four research publications are discussed in Section 3 in which machine learning has been used for affective design. The reviewed research show that machine learning techniques can be used to develop models which represent the relationships between affective customer needs and design attributes. Based on the models, machine learning can also be used to determine the optimal settings of design attributes for the affective aspects of products in order to achieve the maximum affective satisfaction of customers.

A review article surveyed the computational intelligence techniques for new product development where computational intelligence was one of the mainstream approaches for machine learning (Kusiak and Salustri 2007). In the article, survey data was used by computational intelligence techniques for new product development. A monograph also included a review for using computational intelligence techniques for new product development, where survey data was used in the techniques (Chan, Kwong, and Dillon 2012). Following these, two special issues have developed to include research articles on similar topics (Chan et al. 2014, Chan et al. 2016). In those articles, computational intelligence techniques were discussed to address both functional and affective components for new product development. The literatures reviews reveal that many review articles have been written to discuss systematical and empirical methods for new product development (Graner and Missler-Behr 2012, Fettermann and Echeveste 2014). However, there is still a lack of a specific review article to solely survey machine learning techniques for affective design which is an important component in new product development despite optimizing the functional aspects in product development. Therefore, this motivates this article in order to survey the machine learning techniques for affective design. The article also attempts to provide guidance in using the machine learning techniques when affective design is conducted.

Despite the lack of review articles for affective design, concerns are appeared from the research articles in which survey data is generally used for affective design. First, limited Kansei words are used in the survey questionnaires which are pre-defined 
by product designers based on their experience and judgment. Hence, the whole affective domain for a particular product type cannot be covered. Second, the survey relies on conscious responses to the affective qualities of the products. Participants may also have difficulties in expressing their internal opinions through particular scales on the survey questionnaires or consumer interviews. Hence, a consumer survey alone may not provide complete affective information for product development. Thanks to advanced computational technologies, 2.5 quintillion bytes of "big data" can be captured daily from a wide range of sources such as pervasive sensor networks, internet services, webs, blogs and social media (StorageServers 2016). Such "big data" has raised interest in capturing useful information for developing company strategies, marketing campaigns and identifying product preferences (Bello-Orgaz and Jason 2016). Many consumers are influenced by social media, like consumer blogs, and product twitters, when deciding on their purchases (Jin et al. 2016). Also through sensor and mobile networks, smart affective systems (Katarya and Verma 2016, Wang and Chin 2016) can be used to capture "big data" involving the facial expressions and even intonation of the voice of consumers, where this data reflects consumer perceptions on various affective issues of products. Hence, social media or smart affective systems contain valuable information for product designers to generate the affective design of new products. So far, not much research has been attempted on capturing consumer reviews or physiological response from data big so as to generate useful information for affective design, although the big data size grows exponentially. The challenges and prospects in using big data for affective designs are therefore discussed, but we do not suggest replacing survey data with big data. The authors hope this article will provide a valuable framework and guidance for researchers who are interested in exploring big data and machine learning technologies for affective design.

The rest of this article is organized as follows: Section 2 presents the purposes of affective design and Kansei engineering. Section 3 presents an extensive overview of affective design based on survey data and machine learning, and discusses the limitations of the current affective design technologies using survey data. Section 4 discusses the prospects in using big data to enhance affective design. 


\section{Affective design and Kansei Engineering}

\subsection{Affective design}

As perceptual information provides the involved media to convey product value to potential customers, affective design is essential to establish customers' cognition of a product. Affective design involves the processes of identifying, measuring, analysing, and understanding the relationship between the affective needs of the customer domain and the perceptual design elements in the design domain (Lai, Chang, and Chang 2005). Perceptual design attributes such as colour, shape and material of a product can evoke the affective responses of customers to a product. Affective design can excite customers' psychological feelings and improve customer satisfaction in emotional aspects. As products with good affective design can positively affect customers' choice of products (Creusen and Schoormans 2005, Noble and Kumar 2008), it is essential to enhance affective satisfaction in customer-driven product development.

Affective design involves a mapping process from the affective customer needs to the design elements (Jiao, Zhang, and Helander 2006). Taking mobile phone design as an example, affective customer needs can be indicated by Kansei words such as Dazzling, Dignified, and Cute, where different mobile phones are developed with different perceptual design elements. Customers have different affective reactions when mobile phones with different interfaces and different shapes are shown. To satisfy customers' affective design needs, it is necessary for product designers to map affective design needs to perceptual design elements such as product colour, interfaces.

Despite the machine learning technologies for affective design, there are two other types of techniques for affective design. The first type is based on the frameworks for affective design such as Kansei Engineering framework (Nagamachi 1995), decision support framework (Barnes and Lillford 2009) and the conceptual affective design framework (De Byl 2015). The frameworks attempt to provide structured processes to practitioners for conducting affective design. Another type is based on the perceptual techniques which are commonly used by designers such as creating mood and theme boards, ethnography, perceptual mapping and sensory testing (Takahashi 1999 and Baxter 1995). Both types of techniques are easy to be applied but are incapable of dealing with data. The outcomes of applying the techniques are highly dependent on the experience, 
skills and subjective judgments of designers. On the contrary, when applying machine learning technologies on affective design, the experience, skills and subjective judgments of designers are not necessarily required. Overall, machine learning technologies are effective to associate with data for affective design.

\subsection{Kansei Engineering}

Affective design was established as Kansei Engineering (KE) (Nagamachi 1995) which is used to transform emotional impressions to perceptual design attributes/elements. "Kansei" is a Japanese word which expresses psychological feelings, sensations, and emotions (Nagamachi 1995). Kansei engineering unites Kansei into the engineering realm in order to design products which satisfy customers' emotional needs (Nagamachi 2010).

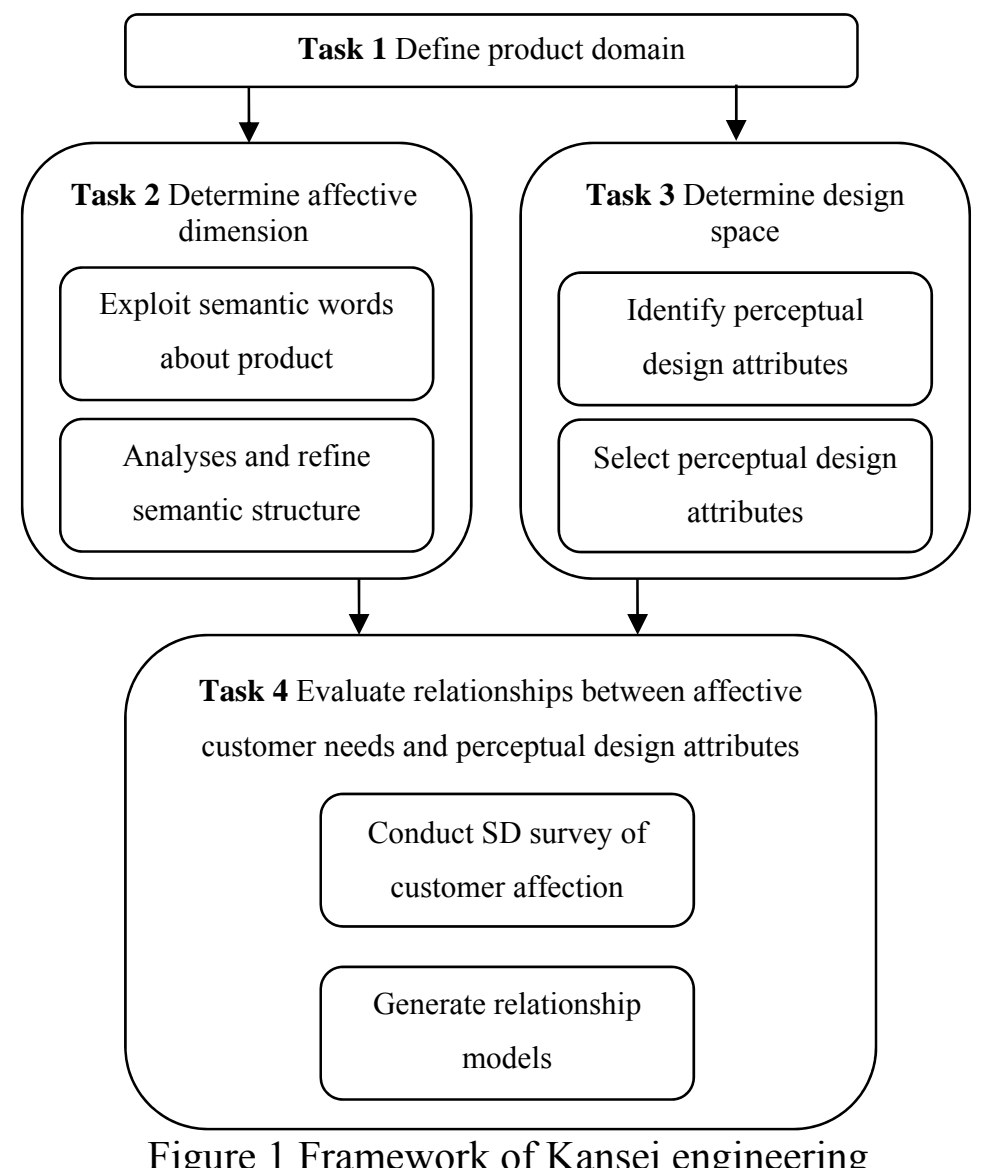

As shown in Figure 1, the framework of Kansei engineering encompasses four tasks (Nagamachi 1995, Barnes and Lillford 2007), namely defining product domain, determining affective dimensions, determining design spaces and evaluating the 
relationships between affective customer needs and perceptual design attributes.

Task 1 Defining product domain refers to identifying the products to be studied. Different sets of words can be used to describe affective customer needs in different product domains. Kansei engineering attempts to study the homogenous semantic structure of a product, in order to assess the overall aesthetic judgments (Chang 2008).

Task 2 Determining affective dimensions: Semantic words can be used to describe the various dimensions of affective customer needs in the product domain, such as modern-traditional, simple-complex, dazzling/luxurious-ordinary, high-techclassic and comfortable-uncomfortable (Yadav et al. 2016). As a product can be associated with multiple dimensions of affective customer needs, the Kansei engineering framework attempts to identify the semantic words associated with a product domain and to determine the most appropriate semantic words for representing the fundamental dimensions of the affective customer needs. Two methods, qualitative and quantitative, can be used to determine the dimensions. Qualitative mapping methods involve affinity diagrams and category classification methods (Nagamachi 2010). Quantitative methods involve multivariate statistical analyses, such as factor analysis, principal component analysis, and multidimensional scaling (Nagamachi 2010).

Task 3 Determining design spaces: In Kansei engineering, morphological analysis is generally used to identify and categorise perceptual design elements of a product category (Chang 2008, Nagamachi 2010). Morphological analysis systematically structures and exploits the candidate solution based on a "morphological matrix". Morphological analysis is effective in generating new product concepts by reassembling the selected options of the perceptual design attributes. After the perceptual design attributes are extracted, the Pareto diagram is used to select the more significant ones (Lanzotti and Tarantino 2008).

\section{Task 4 Evaluating relationships between affective customer needs and} perceptual design attributes: Survey questions and questionnaires can be used to study the relationships between affective customer needs and perceptual design attributes, where affective customer needs and perceptual design attributes are identified based on Tasks 1 to 3. The survey attempts to determine customers' affective experience. In the survey, a Semantic differential method 
(SD) is generally used to study customer affections from product domains (Jiao, Zhang, and Helander 2006, Barnes and Lillford 2009, Nagamachi 2010). The SD uses $N$-point psychometric scales to map affective customer needs into discrete opinion scores. SD questionnaires have been used to collect affective customer needs (Akay and Kurt 2009, Kongprasert et al. 2008, Zhai, Khoo, and Zhong 2009a).

As an illustration, an online questionnaire in Figure 2 was developed based on five-point psychometric scales to collect data of affective customer needs (Chan, Kwong, and Dillon 2012, Fung et al. 2012). The online questionnaire was developed based on 32 mobile phones made by various manufacturers which had nine perceptual design attributes as illustrated in Table 1. The online questionnaire surveyed the appearance of the mobile phones regarding four affective dimensions namely, "simple or complex" (S-C), "unique or general" (U-G), "high-tech or classic" (H-C), and "handy or bulky" (H-B). The opinion scores were given in five ranks, where 1 is the lowest and 5 is the highest. The front and side views of the mobile phones were presented. When consumers were surveyed, the four affective dimensions were scored based on the five-point psychometric scale.

Based on the survey data, the optimal settings of the perceptual design attributes can be determined to achieve the maximum overall affective customer affective satisfaction using appropriate methods. 


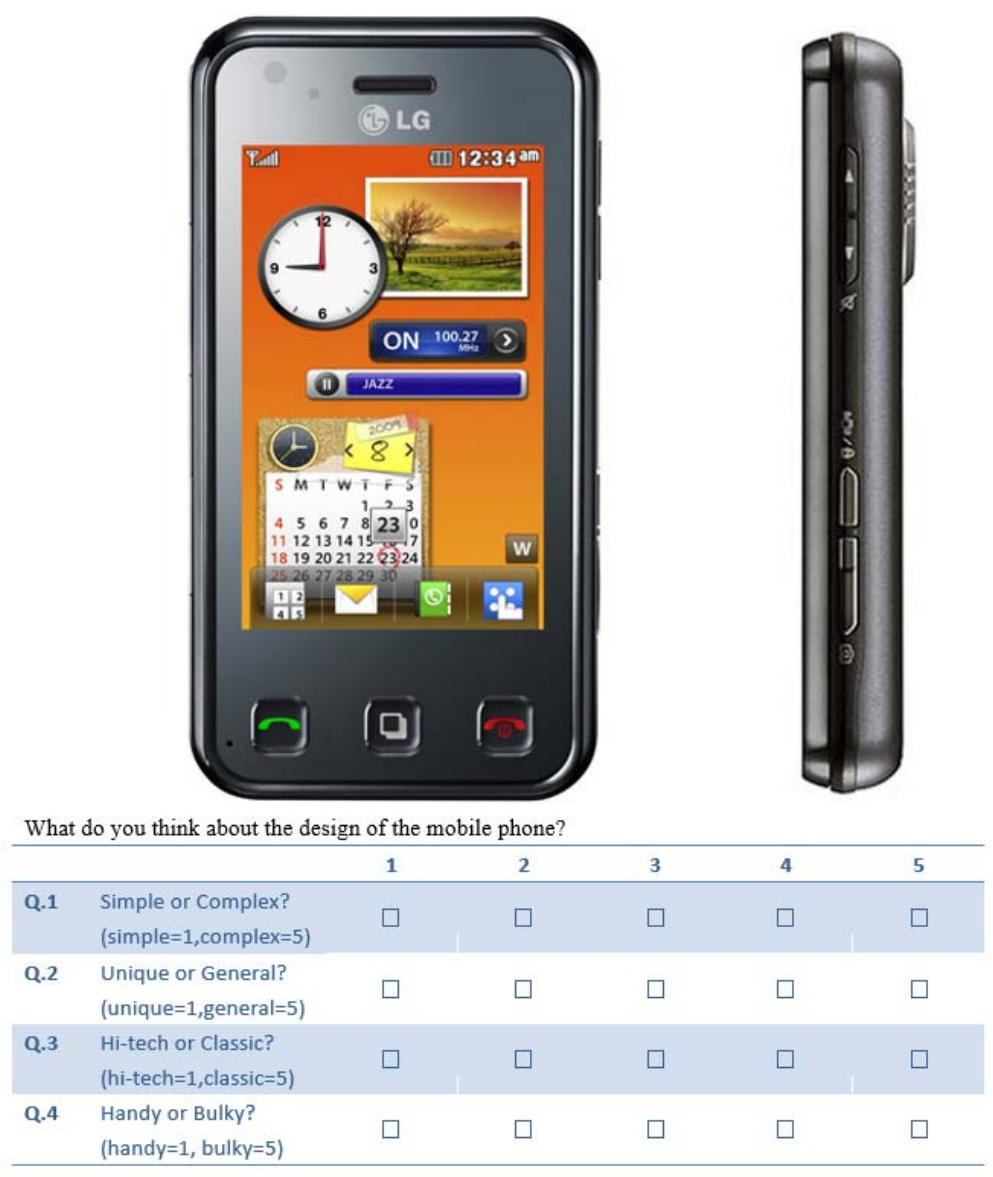

Figure 2 Questionnaires for mobile phones 
Table 1 Perceptual design elements of mobile phones

\begin{tabular}{|c|c|c|c|c|c|c|}
\hline $\begin{array}{l}\text { Alternative } \\
\text { Design } \\
\text { Attributes }\end{array}$ & 1 & 2 & 3 & 4 & 5 & 6 \\
\hline Top Shape & $\begin{array}{l}\text { Line and } \\
\text { no fillet }\end{array}$ & $\begin{array}{c}\text { Line and } \\
\text { small fillet }\end{array}$ & $\begin{array}{c}\text { Arc and } \\
\text { small fillet }\end{array}$ & Irregular & Curve & \\
\hline Bottom Shape & $\begin{array}{l}\text { Line and } \\
\text { no fillet }\end{array}$ & $\begin{array}{l}\text { Line and } \\
\text { small fillet }\end{array}$ & $\begin{array}{l}\text { Arc and } \\
\text { small fillet }\end{array}$ & Irregular & Curve & \\
\hline Side Shape & $\left.\right|_{\substack{\text { Trapezoidal } \\
\text { rear }}}$ & Rounded end & Parallelogram & Bowed & $\begin{array}{l}\text { Trapezoid } \\
\text { fore }\end{array}$ & Polygonal \\
\hline $\begin{array}{c}\text { Function Button } \\
\text { Shape }\end{array}$ & Round & $\begin{array}{l}\text { Square and } \\
\text { round inner }\end{array}$ & Small squares & Large square & Wide large & \\
\hline $\begin{array}{l}\text { Number Buttons } \\
\text { Style }\end{array}$ & \begin{tabular}{|l|l|l|} 
& & \\
& & \\
& & \\
& & \\
\end{tabular} & \begin{tabular}{|l|l|} 
& \\
& \\
& \\
Shaped grid \\
\end{tabular} & $\begin{array}{l}b \infty \\
b \infty 5\end{array}$ & One piece & & \\
\hline Layout & 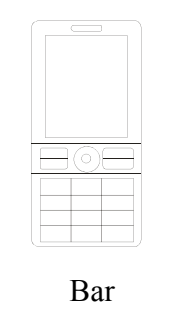 & $\begin{array}{l}-(0)-7) \\
\text { Slide }\end{array}$ & $\begin{array}{c}\square \odot \square \\
\text { Large screen }\end{array}$ & & & \\
\hline Screen size & $\leqq 2.2$ in & $2.4-2.8$ in & $\geqq 3$ in & & & \\
\hline Thickness & $\leqq 10 \mathrm{~mm}$ & $11-14 \mathrm{~mm}$ & $15-18 \mathrm{~mm}$ & $\geqq 19 \mathrm{~mm}$ & & \\
\hline Weight & $\leqq 80 \mathrm{~g}$ & $83-100 \mathrm{~g}$ & $101-120 \mathrm{~g}$ & $125-140 \mathrm{~g}$ & $141-149 \mathrm{~g}$ & $\geqq 150 \mathrm{~g}$ \\
\hline
\end{tabular}

Various machine learning technologies were developed for affective design and Kansei engineering, particularly for Task 4. The next section shows a review of technologies which are commonly used in affective design and Kansei Engineering. 


\section{Affective design using machine learning}

This section discusses the use of machine learning for affective design. We first introduce the definition, purpose and relevant catalogues of machine learning. Machine learning is defined as "A computer program is said to learn from experience $E$ with respect to some class of tasks $T$ and performance measure $P$, if its performance at tasks in $T$, as measured by $P$, improves with experience $E "$ (Mitchell 1997). In other words, machine learning uses computational programs in order to improve the performance of certain tasks when past experience of those tasks is available and is learnt by computer. Machine learning technologies are catalogued by two classes, namely statistical regression and artificial intelligence. Statistical regression includes with linear regression, multivariate regression and logistic regression (Rawlings 1988). Artificial intelligence includes the approaches of neural networks, support vector machines, fuzzy methods, association rule mining, rule based systems, and evolutionary computation (Rich, Knight, and Nair 2009).

After the affective data are collected based on the approaches in Section 2, machine learning can be used to perform affective design which is involved with three tasks, namely affective modelling, knowledge discovery, and determination of optimal design attribute settings. The three tasks are illustrated in Figure 3. The first task, affective modelling, attempts to develop a model that relates design attributes to affective customer needs. Machine learning, including statistical regression and artificial intelligence, are commonly used to establish the relationships between perceptual design attributes and affective customer needs (Chan, Kwong, and Dillon 2012). Based on the models, machine learning can be used to perform the third task which attempts to determine the optimal attribute settings for affective design. As nonlinearity generally exists between perceptual design attributes and affective customer needs, determination of the optimal perceptual design attributes is a generally nonconvex problem with multi-optima. Machine learning techniques such as heuristic algorithms, and evolutionary computation are generally used (Chan, Kwong, and Dillon 2012), as they are effective in searching for near-optimal solutions for many design optimization problems which involve multi-objectives and multi-optima (Saridakis and Dentsoras 2008a). The second task, knowledge discovery, attempts to visualize information from affective data, where association rule mining and rule based systems can be used. The information attempts to interpret the relationships between perceptual design elements and affective customer needs in products. 
The research articles discussed in this Section have been published from 1997 to 2018. The research articles were collected based on a search engine namely Engineering Village. We used keyword affective design and Kansei in order to search for the relevant articles. Ninety-four articles were collected, and the articles were classified in terms of the machine learning technologies used. The definition of machine learning in (Mitchell 1997) was used as a guidance to determine whether the article is relevant to machine learning. For affective modelling, statistical regression and artificial intelligence are classified, where artificial intelligence is included with the technologies of neural networks, support vector machines, fuzzy expert systems, fuzzy neural networks, and fuzzy regression. For knowledge discovery in affective data, the approaches of association rule mining, and rule based systems based on the rough set and the grey set are commonly used. For determination of the design attribute settings for affective design, the technologies of conjoint analysis, single objective optimization, multi-objective optimization have been developed. The headings of the subsections are deployed based on this classification of technologies.

This section is organized as follows: Section 3.1 discusses the first task and the commonly used machine learning approaches for affective modelling, where models are developed to relate perceptual design elements of a new product to its affective customer needs. Section 3.2 discusses the second task, where rule mining is used for extracting useful affective information from survey data. Section 3.3 discusses the third task and heuristic methods, which attempt to determine the optimal perceptual design elements for maximising the affective satisfaction of customers. Section 3.4 discusses the limitations of the currently used machine learning technologies for affective design.

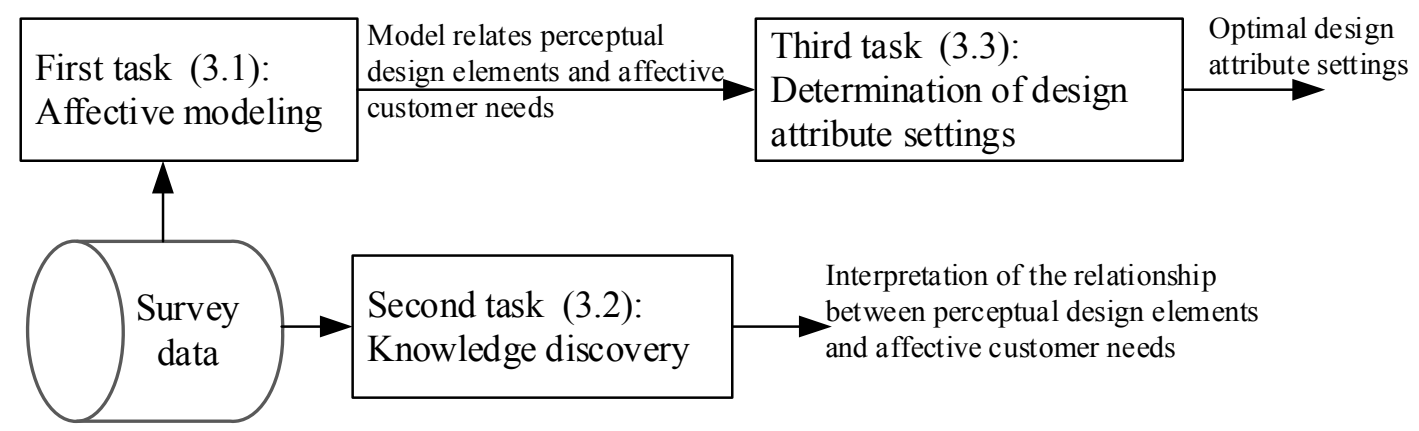

Figure 3 Three tasks for affective design using survey data 


\subsection{Affective Modelling}

Various machine learning techniques have been employed to relate perceptual design elements, and affective customer needs in products (Barnes and Lillford 2007). They can be classified into two approaches; namely statistical regression and artificial intelligence.

\subsubsection{Statistical regression}

In new product development, statistical regression has commonly been used, as one can find explicit information such as interactions between design variables and variable significances (Tanoue, Ishizaka, and Nagamachi 1997). Multiple linear regression has been used to model the relationships between usability and design elements (Lanzotti and Tarantino 2008). In affective design, multiple linear regression (Kuang and Jiang 2008, Lin and Wei 2016, Bahn et al. 2009, Wang and Ju 2013, Oztekin et al. 2013) has been used to model the relationships between perceptual design attributes and affective customer needs. Nagamachi (Nagamachi 2010) applied partial least squares regression based on the data projected by principal component analysis. The major limitation of applying multiple linear regression is that only qualitative data can be addressed but not categorical data (Aktar, Anagun, and Koksal 2009). Barone et al. (Barone, Lombardo, and Tarantino 2009) proposed a logistic regression in modelling ordinal affective data which is common in the product evaluation of affective satisfaction. Adjustable weights are introduced in the logistic regression to further improve the fitting capability.

These regression approaches require the assumptions that perceptual design attributes are linear with affective customer needs, and that the effect of a perceptual design attribute is constant throughout the entire range of the affective customer needs. To satisfy these assumptions, more perceptual design attributes are required to fit a wider range of affective customer needs. Hence, the model is more complex and more difficult to interpret when more perceptual design attributes are involved (Han et al. 2000). Also, evaluation of affective dimensions involves human subjective judgments which are inherently imprecise. Hence, the assessment which represents a source of uncertainty and bias is typically neglected in the regression models, which correlate perceptual design attributes and affective customer needs. 


\subsubsection{Artificial intelligence}

Compared with statistical techniques, artificial intelligence techniques are generally more capable of dealing with ambiguous survey data for affective design and the modelling of nonlinear relationships between affective customer needs and design attributes. Artificial intelligence techniques, neural networks, support vector machines (SVM), fuzzy expert systems, fuzzy regression and hybrid approaches, have been applied on affective design.

Neural network is a biologically inspired computational model formed from a number of artificial neurons which are connected with weights. The neurons in the input layer receive input information and propagate them to the neurons in the hidden layer. The weighted sums from one or more hidden layers are then propagated to the output layer which presents the final outputs of the network (Sze, Chen, Yang, and Emer, 2017). Neural networks have been applied in affective design, as they are more capable to model nonlinear relationships compared with statistical regressions. The multilayer neural network has been proposed to model nonlinear relationships between perceptual design elements and affective customer needs for office chairs (Hsiao and Huang 2002), mobile phones (Lai, Lin, and Yeh 2005), form-colour matching (Lai et al. 2006, Lin, Yeh, and Hung 2008, Zhou et al. 2017), motorcycle helmets and paddle tennis rackets (Diego-Mas and Alcaide-Marzal 2016). A radial basis function was introduced into a neural network to evaluate various cultural factors for affective design (Chen, Khoo, and Yan 2003). The radial basis function simulates the bell-shaped distribution as in fuzzy inference systems, and it attempts to model uncertainty caused by affective quality evaluations (Jang and Sun 1993). The approach is more capable for affective modeling, which normally involves a high degree of uncertainty. To further enhance the capability of modelling the nonlinear relationships between perceptual design attributes and affective customer needs, Chen et al. (Chen, Khoo, and Yan 2006) integrated hierarchal analysis and a Kohonen self-organising map into a neural network. Their approach found that less training data was required, as a nonlinear clustering was adopted to perform the unsupervised learning. Also Ling et al. (Ling et al. 2014) developed a wavelet function based neural network for affective design. Shen and Wang (Shen and Wang 2016) adopted a multi-linear regression and backpropagation neural network to build the relationship between Kansei words and design elements. 
Although neural network approaches are able to model the nonlinear relationships between perceptual design attributes and affective customer needs, the models are in the form of a simplified black-box structure and lack of transparency.

Support vector machines (SVM) are developed based on the principle of structural risk minimization which attempts to minimize an upper bound of the generalization error rather than minimizing the training error. SVM has been adopted to model the affective relationships in product design. Shieh and Yang (Shieh and Yang 2008) proposed a one-versus-one fuzzy SVM approach to develop a classification model of product form design based on customer preferences, and the results of the experiment showed that fuzzy SVM performed better than SVM. Similar to the fuzzy approach, SVM has been proposed based on grey sets in order to address the perceptions when people are evaluating the affective quality (Wang 2011). Support vector regression is an extension of SVM by introducing an $\varepsilon$-insensitive loss function to solve function estimation problems. Yang and Shieh (Yang and Shieh 2010) employed support vector regression to develop a model for predicting consumer affective responses of product forms, where a real-coded genetic algorithm was used to determine the training parameters of the support vector regression model. Yang (Yang 2011a) integrated support vector regression and multi-objective genetic algorithm to construct a hybrid Kansei engineering system based on multiple affective responses. Fan et al. (Fan, Chiu, and Yang 2014) and Yang (Yang 2011b) developed a support vector regression approach to model the relationship between customers' affective responses and design attributes. The results showed that the overall performance of the support vector regression models was superior to the neural networks models.

Fuzzy expert system: Despite using neural networks to model nonlinearities between perceptual design attributes and affective customer needs, a fuzzy expert system was proposed in affective design (Shieh and Hsu 2013). The approach has been applied in fashion products (Lai et al. 2006) and car forms (Syutono et al. 2016). Lin et al. (Lin, Lai, and Yeh 2007) proposed a fuzzy logic approach for the affective design of mobile phones. They showed that their developed fuzzy models outperformed the neural network-based models in term of generalization capability. Also, unlike neural networks which are a black-box typed modelling approach and explicit information is difficult to be extracted, information on the relationships between perceptual design 
attributes and affective customer needs can be obtained from the fuzzy expert system.

Fuzzy neural networks: The fuzzy neural networks approach combines the capability of fuzzy logic in the linguistic representation of knowledge and the adaptive learning capability of neural networks for modeling. The fuzzy neural network is a multilayer feed-forward network in which the neural network is regarded as a learning algorithm and fuzzy reasoning is used to map inputs into an output (Wang and Elhag, 2008). The network uses a series of output nodes of neural networks to emulate a fuzzy membership grade of an input and then determines the aggregate value of an output through defuzzification. The approach has been used for affective modeling in previous studies (Sun et al. 2000, Tsai, Hsiao, and Hung 2006, Akay and Kurt 2009). Hsiao and Tsai (Hsiao and Tsai 2005) proposed a neural network-based fuzzy reasoning approach for modelling the relationships between design attributes and customers' affective image. An adaptive neural fuzzy inference system (ANFIS) (Jang 1993) was developed to generate nonlinear and explicit customer satisfaction models for new product development (Kwong, Wong, and Chan 2009) and affective design (Kwong et al. 2013). Based on the fuzzy rules generated in the fuzzy neural networks, explicit relationships between perceptual design attributes and affective customer needs can be obtained (Kwong, Wong, and Chan 2009). Jiang et al. (Jiang, Kwong, Siu, et al. 2015) proposed a rough set and particle swarm optimization based-ANFIS approach to model customer satisfaction for affective design. The proposed modelling approach is effective for predicting customer satisfaction when the product prototypes are given.

Explicit information on affective design can be extracted based on fuzzy neural networks and fuzzy expert systems. They overcome the limitation of neural networks where explicit information is difficult to be extracted. The generalization capabilities of neural networks are generally better than those fuzzy methods, as the size of the neural network is more flexible and can be expanded to model any system nonlinearity. This is a tradeoff in deciding whether to use neural networks or fuzzy methods, where one needs to decide on obtaining better generalization capability or more explicit information.

Fuzzy regression: Evaluating the affective design of products involves human opinion judgements which are subjective and inherently imprecise. Neural networks and 
statistical regression cannot address the uncertainty due to human subjective judgements in affective design. To address the fuzziness, fuzzy regression was proposed by Shimizu and Jindo (Shimizu and Jindo 1995), Sekkeli et al. (Sekkeli et al. 2010) and Kwong et al. (Kwong et al. 2010) in modeling the relationships between affective customer needs and perceptual design attributes. Fuzzy regression is a fuzzy type of classical regression analysis in which the coefficients in the model are represented by fuzzy numbers. It aims to find a regression model that fits all observed fuzzy data using a specified fitting criterion. In affective design, the fuzzy regression approach attempts to account for the fuzziness when evaluating various affective dimensions of products. To enhance the generalization capability of modelling the nonlinearity between affective customer needs and perceptual design attributes, genetic programming based fuzzy regression was also been proposed to model affective relationships (Chan et al. 2011), where the polynomial of the fuzzy regression was generated by the genetic programming and the fuzzy coefficients were determined by Tanakia fuzzy regression (Tanaka, Uejima, and Asai 1982). To enhance the generalization capability of estimating the uncertainty in evaluating affective design, more flexible spread based fuzzy regressions have been proposed by integrating with genetic computational algorithms (Chan and Engelke 2017, Chan et al. 2017, Kwong, Jiang, and Luo 2016).

Compared with fuzzy neural networks and fuzzy expert systems, explicit information can be directly indicated from fuzzy regression models which are in polynomial forms. Also, the interaction and significance of the regressors can be indicated. However, the generalization capabilities of fuzzy neural networks and fuzzy expert systems are generally better than those fuzzy regression methods. One needs to perform a trade off between the generalization capabilities and capabilities in obtaining explicit information while choosing a technique for affective modeling.

\subsection{Knowledge discovery in affective data}

Sometimes, explicit information may not be easily obtained from complex mathematical models which relate affective customer needs and perceptual design attributes. Rule based systems can be used to help interpret the relationships. Previous research approaches adopted association rules, rules with rough sets and grey sets to interpret the relationships. 


\subsubsection{Association rule mining}

Association rule mining is commonly used to discover frequent item-sets as rules from a large database. It has been employed to generate rules for affective design. Jiao et al. (Jiao, Zhang, and Helander 2006) developed an association rule system to generate rules from frequent item-sets in a large database, where the item-sets correlate affective customer needs and perceptual design elements. The association rules are mostly represented as 'affective customer needs $Y \Rightarrow$ perceptual design elements $X$ '. In the association rule set, a goodness index indicates the accuracy of a particular association rule by comparing actual affective scores with the scores estimated by the rule system (Jiao, Zhang, and Helander 2006, Yang and Shieh 2010). Based on the association rules, significant perceptual design attributes can be identified. Also, unlike statistical analyses which may lose information caused by analysing expected values in the affective dimensions, the rules cover all information in the range of an affective dimension (Aktar, Anagun, and Koksal 2009). Park and Han (Park and Han 2004) developed fuzzy rulebased models for explaining the relationships between affective customer needs and product design attributes. Jiao et al. (Jiao et al. 2008) developed an association rule system with ambient intelligence in order to recommend design attributes for a particular perceptual design element and facilitate the interactive decision-making of affective design.

Ambiguity exists in affective design evaluation as it involves human subjective judgement. Association rules only show the mapping between quantity domains of perceptual design attributes and affective customer needs. The ambiguity in affective design evaluation has not yet been addressed. In the following subsection 3.2.2, the theories of the rough set and grey set are adopted in the associate rule mining in order to address the ambiguity in evaluating affective quality.

\subsubsection{Rule based systems based on Rough set and grey set}

To address ambiguity in affective design evaluation, Nagamachi (Nagamachi 2010) adopted rough set theory to address uncertainty in ambiguous data. The lower and upper approximations of affective customer needs are bounded in the rough set, where the lower approximations are certainly classified in the target classes and the upper approximations are vaguely covered in the target classes. When the lower and upper approximations are different, the approximations in the boundary region cannot be certainly classified into a 
class. Rough sets can be used to indicate uncertainties of approximations. The basic concept of rough set theory is to formulate an approximation of a crisp set from vague or imprecise information. Hence rough set theory can be applied in affective design evaluation which is ambiguous or subjective.

A study of Okamoto et al. (Okamoto, Nishino, and Nagamachi 2007) found that the rough set approach was more reliable in affective design evaluation compared with statistical regression especially in the existence of the interactions among design attributes. To further enhance the generalization capability, Bayesian rough sets theory was adopted to perform rough set-based rule mining for affective design (Nishino, Nagamachi, and Tanaka 2006, Zhai, Khoo, and Zhong 2009b). Zhou et al. (Zhou et al. 2009 ) introduced a rough set-based rule mining to generate association rules for affective design, where significant rules were extracted based on an importance metric. Zhai et al. (Zhai, Khoo, and Zhong 2009a) further introduced dominance-based rough set theory in affective rule mining by which an approximation to ordinal data can be generated. Shi et al. (Shi, Sun, and Xu. 2012) developed an association rule system based on rough set theory which generated rules by including additional perceptual design attributes into the key elements and the selected final rules are based on the support and confidence thresholds. Fung et al. (Fung et al. 2012) employed a multi-objective genetic algorithm approach to generate approximate rules that can be used to determine the lower and upper limits of the affective dimensions of a product when the perceptual design attributes are specified. Wang proposed a framework based on rough set theory to correlate design attributes of new products and affective features which are evaluated subjectively by users (Wang 2018). Decision rules based on rough sets theory can be used to determine the optimal affective design.

Despite using rough sets, grey theory can be used to illustrate uncertain information (Deng 1982), when the amount of affective data is small (Lai, Chang, and Chang 2005, Shieh, Yeh, and Huang 2016). Hsiao and Liu (Hsiao and Liu. 2002) used grey sets to model the relationship between a single perceptual design attribute and the affective customer need. The developed model was implemented in a computer-aided design system to recommend a perceptual design element corresponding to a specified affective dimension. Lai et al. (Lai, Lin, and Yeh 2005) expanded the single-perceptual design attribute model to a multi-variable one. 
One of the limitations of rough set and grey set approaches is that the approaches can only be applied on affective design with categorical data and not quantitative ones. Although discretisation can be used to transform quantitative attributes into categorical attributes such that both the rough set and grey set approaches can be applied, some information contained in the original dataset may be lost and also the intervals of continuous attributes can only be defined roughly.

\subsection{Determination of Design Attribute settings for Affective Design}

In affective design, an optimal setting of perceptual design elements needs to be determined in order to achieve the maximum affective needs. To perform the optimization, conjoint analysis, classical optimization methods, and heuristic methods have been used.

Conjoint analysis attempts to determine an appropriate combination of perceptual design attributes which is significant to the affective qualities. Conjoint analysis was employed to aid to determine the optimal setting of design attributes in new product development (Shi, Olafsson, and Chen 2001). Conjoint analysis attempts to determine the relative importance consumers attributes to salient attributes and the utilities they attach to the levels of attributes. Hong et al. (Hong, Han, and Kim 2008) proposed a variant of multiple response surfaces methodology to consider multi-affective customer needs by which appropriate sets of design attributes were obtained. Akay and Kurt (Akay and Kurt 2009) adopted an ordinal logistical regression approach with conjoint analysis in order to determine optimal design attribute settings by maximizing the overall preference scores. Yadav et al. (Yadav et al. 2016) combined conjoint analysis, the Kano model, the Taguchi method and grey relation analysis in order to obtain the optimal combination of shape parameters and aesthetic aspects. Conjoint analysis has also been integrated with Kansei engineering for the affective design of digital cameras (Wang 2015).

Single objective optimization: Simpson (Simpson 2004) formulated a single-objective optimization problem which involved an affective customer need, and nonlinear programming algorithms were developed to solve the problem for determining the optimal setting of the perceptual design elements. Aktar et al. ( Aktar, Anagun, and Koksal 2009) developed a statistical regression model which correlates affective customer needs and perceptual design elements. Based on the models, the best levels 
of affective design attributes for visual perceptions are determined by maximizing the affective customer satisfaction.

Multi-objective optimization: Heuristic algorithms such as genetic algorithm (GA) are commonly used in design optimisation. GA is effective to search for near-optimal solutions for many design optimization problems which involve multi-objectives and multi-optima (Saridakis and Dentsoras 2008b). Hsiao and Tsai (Hsiao and Tsai 2005) used GA to search for an optimal design which satisfied the required product image. Jiao et al. (Jiao et al. 2008) employed a GA to optimize affective design for mass customization and personalization of product ecosystems. Yang and Shieh (Yang and Shieh 2010) adopted GA to determine the parameter settings in support vector regression for predicting the affective responses on product form design. Fung et al. (Fung et al. 2014) proposed a guided search GA approach to determine the optimal design attribute settings for affective design. GAs have been used for solving various multi-objective and multi-optima design problems, such as product portfolio planning (Jiao, Zhang, and Wang 2007), and generative design (Yanagisawa and Fukuda 2005). Also, they have been used to determine the optimal setting of perceptual design attributes for multi-affective dimensions (Hsiao and Tsai 2005, Jiao et al. 2008, Yang and Shieh 2010, Jiang, Kwong, Liu, et al. 2015, Shieh, Li, and Yang 2018, Guo et al. 2014). Another population based optimization method namely, particle swarm optimisation algorithm, has been proposed to develop association rules for the affective design of compact cars (Jiang et al. 2018). The algorithm was used to develop an association rule based system to correlate design attributes and affective dimensions.

\subsection{Limitations of the current affective design using traditional survey data}

Previous studies of affective design mainly involved conducting consumer surveys based on questionnaires and interviews to collect consumers' views, preferences and comments regarding affective issues of products. Some limitations of the surveys can be observed as shown below:

Limited numbers of Kansei words: When consumer surveys are designed, a limited number of Kansei words are usually used in order to create brief questionnaires or interviews. For example, in a survey involved with the assessment of 6 Kansei words on 20 product samples, respondents are required to make assessment 120 times (i.e. 
$120=6 \times 20$ ). The respondents are likely to lose patience in continuing to conduct the survey. More assessments are required, when more Kansei words are included in the survey. Therefore, only a limited number of Kansei words can be included in consumer surveys.

Expensive survey cost and time delay: Conducting consumer surveys can be quite expensive especially involving interviews. On the other hand, it is common to take a period of time to conduct surveys. Thus, it is unavoidable to have some time delays for obtaining full sets of survey data and performing data analysis.

Ignoring physiological responses and sentimental expressions: A consumer survey only records consumers' scores or comments on affective design. The survey cannot take into account consumers' facial expressions and even intonation of their voice which reflect their preferences on affective design of products to a certain extent. Also, the consumer survey data does not contain much sentimental expression which can easily be found in online customer reviews like consumer blogs, and social media.

Consumer opinions excluding in questionnaire: Many potential customers are influenced by online reviews, like product blogs, and social media, when deciding their purchases. In turn, online reviews are sources of valuable information for product designers to generate affective design of new products. Online reviews are generally defined as free texts written by consumers. They are written entirely based on the willingness of consumers, out of their own interests, in their own language, and without any pre-defined questions to lead them. Online reviews provide rich information regarding opinions toward products and include consumer opinions which cannot be included in currently used surveys based on questionnaires and interviews.

Table 2 summarizes the limitations and advantages of using different machine learning technologies for performing affective design. Ones can use this summary to apply machine learning technologies when performing affective design for new products.

Table 3 illustrates the research articles which have been discussed in this Section and have been published from the past to 2018. The number of publications in terms of the machine learning technologies are shown. In the category of affective design, the table shows that the number of articles for statistical regression is much smaller than the total number of those on artificial intelligence. These numbers reflect the fact that artificial 
intelligence technologies are more effective in modelling data which is involved with nonlinearity and uncertainty than statistical regression. In the category of knowledge discovery in affective data, the number of articles for association rule mining is less than the number of rule based systems based on rough set and grey set. These numbers indicate that the approaches of rule based systems based on rough set and grey set are more commonly used, since these approaches are more effective in analysing survey data which is involved with uncertainty, while the approaches of association rule mining are not capable of addressing the uncertainty. In the category of knowledge discovery in affective data, the number of articles for multi-objective optimization are more than for the other two approaches. The more number can be explained by the fact that affective design mostly attempts to optimize more than one objective. Another interesting finding is that the total number of articles generally increased from 2001 to 2007 and the numbers generally decreased from 2009 to 2012. The numbers were more static from 2010 to 2018 . Since those articles were researched based on the analysing of survey data, big data was become more popular. More research is expected to be focused on using big data for affective design. The impact and prospect of using big data for affective design is further discussed in the following section. 
Table 2: Advantages and limitations of using machine learning technologies for affective design.

\begin{tabular}{|l|l|}
\hline & Affective Modelling (Section 3.1) \\
\hline $\begin{array}{l}\text { Purposes on } \\
\text { affective } \\
\text { design }\end{array}$ & $\begin{array}{l}\text { Develop a model which relates perceptual design elements } \\
\text { and affective customer needs in products; the models attempt } \\
\text { to predict affective customer needs when a set of perceptual } \\
\text { design elements is given. }\end{array}$
\end{tabular}

\section{Mechanism $\quad$ Statistical regression}

analysis $\quad$ Advantages: Explicit information can be indicated from the models which is a polynomial form. Sensitivities, significances and interactions for perceptual design elements can be indicated. It compensates the limitation of artificial intelligence which cannot indicate explicit information

Limitations: The model cannot be used to estimate the amount of uncertainty which is caused by customer evaluations of affective needs.

\section{Artificial intelligence (AI)}

Advantages: More accurate predictions can be achieved compared with statistical regression, as highly nonlinearity can be modelled. Some AI methods such as fuzzy expert system, fuzzy neural networks and fuzzy regression can be used to estimate the amount of uncertainty which is caused by customer evaluations of affective needs.

Limitations: Blackbox models are generated by the AI methods. Explicit information between perceptual design elements cannot be indicated.

Note: Fuzzy regression can be used to generate models in fuzzy polynomial forms. Hence explicit information can be indicated. However the generalization capability of fuzzy regression is generally poorer.

\section{Knowledge discovery in affective data}

\section{(Section 3.2)}

Interpret the relationships between perceptual design elements and affective customer needs in products; it discovers explicit knowledge for affective design; it compensates the limitation of models that only predict affective customer needs.

\section{Association rule mining}

Advantages: The approach attempts to generate rules which are contented with affective qualities and perceptual design elements. The association rules are mostly represented as 'affective customer needs $\mathrm{Y} \Rightarrow$ perceptual design elements X'. The explicit relationship between perceptual design elements and affective customer needs can be indicated more clearly comparing with affective modelling

Limitations: Ambiguity exists in affective design evaluation, as human judgement is subjective. The ambiguity in affective design evaluation has not been included by the associate rules.

\section{Rule based systems based on Rough set and grey} set

Advantages: The approach addresses the ambiguity in affective design evaluation. The rules are engaged with rough sets which indicate the uncertainties. The approach attempts to overcome the limitations of associate rule mining.

Limitations: The approaches can only be applied on affective design with categorical data and not the quantitative ones. Although discretisation can be used to transform quantitative attributes into categorical attributes, partial information in the original dataset can be lost.
Determination of Design Attribute settings for Affective Design (Section 3.3)

Determine an optimal setting of perceptual design elements in order to achieve the maximum affective needs for customers.

\section{Conjoint analysis attempts to determine an}

appropriate combination of perceptual design elements which are significant to the affective qualities. Conjoint analysis aids to determine the optimal design attributes and importance consumer attributes for affective needs.

Advantages and limitations: Only an appropriate solution for affective design can be roughly estimated but the computational time is much faster than optimization.

\section{Single objective and Multi-objective optimization} Single objective optimization attempts to determine the optimal setting of perceptual design elements in order to maximize a single affective need, where it uses an affective model which relates a set of perceptual design elements and a single affective need.

Mulit-objective optimization attempts to maximize more than one affective needs, where it uses a multiaffective model which relates a set of perceptual design elements and multi-affective needs.

Integer programming algorithms and heuristic algorithms such as evolutionary algorithms are commonly used for single objective and multiobjective optimizations.

Advantages and limitations: An optimal solution for affective design can be determined but much longer computational time is required than conjoint analysis. 
Table 3 The numbers articles published for different machine learning techniques

\begin{tabular}{|c|c|c|c|c|c|c|c|c|c|c|}
\hline \multicolumn{3}{|l|}{ Years } & $\begin{array}{l}2000 \\
\text { or } \\
\text { before }\end{array}$ & $\begin{array}{l}2001 \\
\text { to } \\
2003\end{array}$ & $\begin{array}{l}2004 \\
\text { to } \\
2006\end{array}$ & $\begin{array}{l}2007 \\
\text { to } \\
2009\end{array}$ & $\begin{array}{l}2010 \\
\text { to } \\
2012 \\
\end{array}$ & $\begin{array}{l}2013 \\
\text { to } \\
2015\end{array}$ & $\begin{array}{l}2016 \\
\text { to } \\
2018\end{array}$ & $\begin{array}{l}\text { Total in } \\
\text { terms of } \\
\text { approach }\end{array}$ \\
\hline \multirow[t]{6}{*}{ Affective modelling } & \multicolumn{2}{|c|}{ Statistical regression } & 2 & 0 & 0 & 5 & 1 & 2 & 1 & 11 \\
\hline & \multirow{5}{*}{$\begin{array}{l}\text { Artificial } \\
\text { intelligence }\end{array}$} & Neural network & 1 & 2 & 3 & 1 & 0 & 1 & 4 & 12 \\
\hline & & Support vector machines & 0 & 0 & 1 & 2 & 4 & 2 & 1 & 10 \\
\hline & & Fuzzy expert system & 0 & 0 & 1 & 1 & 0 & 1 & 1 & 4 \\
\hline & & Fuzzy neural networks & 2 & 0 & 2 & 4 & 0 & 2 & 0 & 10 \\
\hline & & Fuzzy regression & 2 & 0 & 0 & 0 & 3 & 0 & 3 & 8 \\
\hline \multirow{2}{*}{$\begin{array}{l}\text { Knowledge discovery in } \\
\text { affective data }\end{array}$} & \multicolumn{2}{|c|}{ Association rule mining } & 0 & 1 & 2 & 2 & 1 & 0 & 0 & 6 \\
\hline & \multicolumn{2}{|c|}{$\begin{array}{l}\text { Rule based systems based on Rough set and } \\
\text { grey set }\end{array}$} & 1 & 1 & 3 & 4 & 3 & 0 & 2 & 14 \\
\hline \multirow{3}{*}{$\begin{array}{l}\text { Determination of design } \\
\text { attribute settings for } \\
\text { affective design }\end{array}$} & \multicolumn{2}{|c|}{ Conjoint analysis } & 0 & 0 & 0 & 2 & 0 & 1 & 1 & 4 \\
\hline & \multicolumn{2}{|c|}{ Single objective optimization } & 0 & 0 & 1 & 1 & 0 & 0 & 0 & 2 \\
\hline & \multicolumn{2}{|c|}{ Multi-objective optimization } & 0 & 0 & 3 & 4 & 1 & 3 & 2 & 13 \\
\hline \multicolumn{3}{|l|}{ Total in term of years } & 8 & 4 & 16 & 26 & 13 & 12 & 15 & $\begin{array}{l}\text { Overall } \\
\text { total }=94\end{array}$ \\
\hline
\end{tabular}




\section{Future Prospects and Challenges in using Big Data for Affective Design}

So far, very limited research has been attempted on capturing consumer reviews or physiological responses in order to generate useful information for affective design. This section discusses the prospects in using big data to enhance affective design and to tackle the limitations of the current affective design technologies. Big data is involved in social media and smart affective systems which can be used to capture consumer reviews or physiological responses. The challenges in using big data for affective design are discussed, when the data size grows exponentially.

\subsection{Social media for affective design}

Social media such as Facebook, Twitter, LinkedIn, YouTube, and Instagram, are representative and relevant sources of social big data from everyday life (Bello-Orgaz and Jason 2016, Halavais 2015). Big data in social media continues grow in size from multiple distributed sources. This social big data is valuable to support product design decision making and to fulfil customer requirements in developing new products (Jin et al. 2016). Such social big data can intensively benefit affective design. For example, Song and Guido (Song and Guido 2006) proposed communication modes for affective web service design. Song and Vong (Song and John 2013) developed a smart phone interface for affective banking services. 


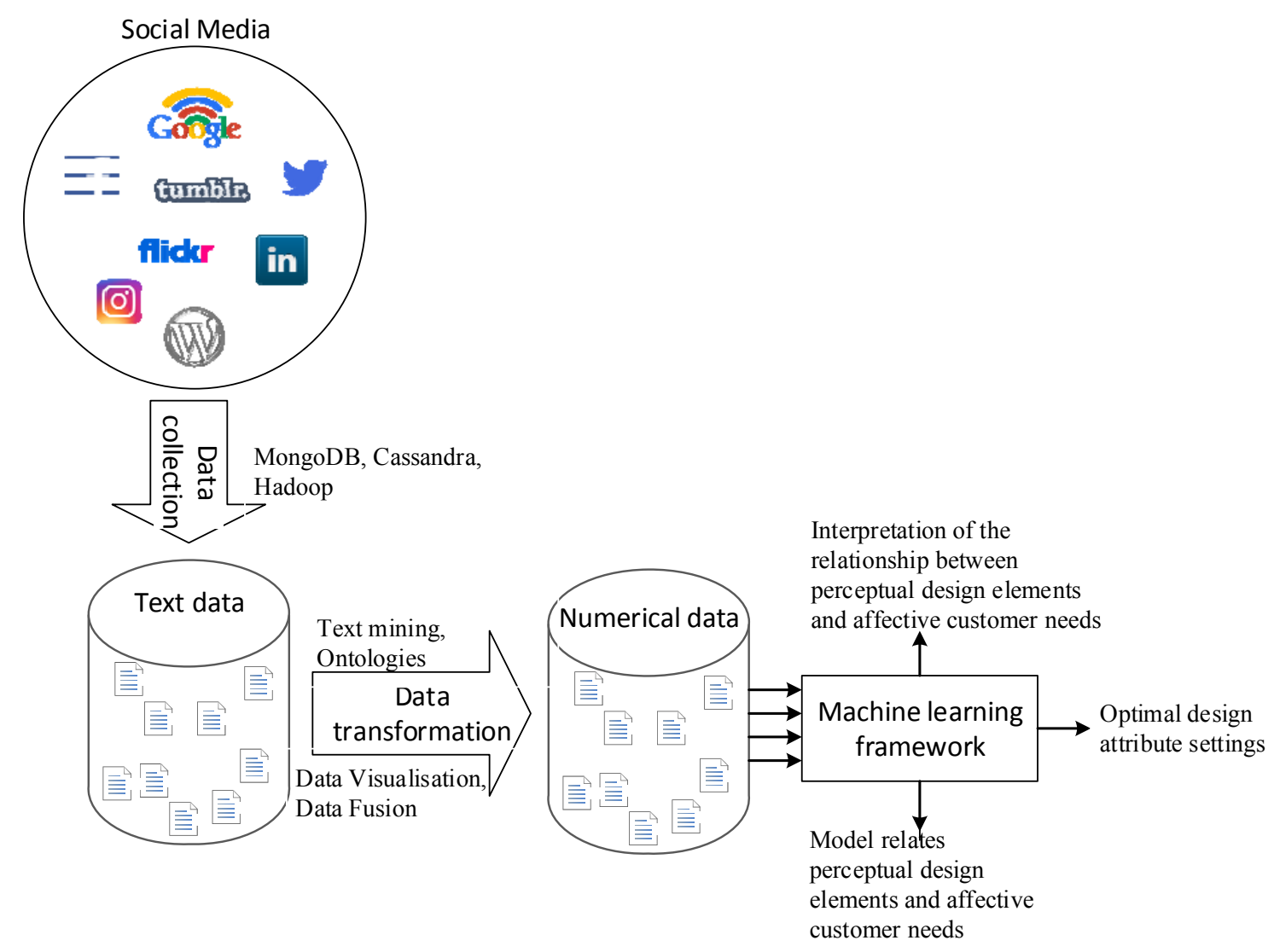

Figure 4: Conceptual flow of using social big data in affective design

Figure 4 shows the conceptual flow of using social big data for affective design. Social media consist of heterogeneous sources of data such as Facebook, Twitter, and Instagram for affective design. These social media data can be collected by big data collection technologies: parallel and distributed processing paradigms such as MongoDB, Cassandra, Hadoop (Bello-Orgaz and Jason 2016). As social media data mostly consists of text data but currently developed affective design frameworks are mostly developed for numerical data, affective design frameworks cannot be used on social media data which is mostly text (Kaisler et al. 2013). It is essential to transform the text data into numerical data before implementation on machine learning frameworks for affective design. Based on the transformed numerical data, the machine learning frameworks discussed in Section 3, such as statistical techniques, and artificial intelligence, can be used to extract and analyse affective design information.

The following sub-sections discuss the commonly used methods, text mining, ontology and data visualisation, to extract numerical information and visual knowledge from social media data which contains heterogeneous content and is in text form. 


\subsubsection{Text mining}

Affective text contents collected from social media can be processed by two dominant statistical techniques namely Latent Dirichlet Allocation (Blei, Ng, and Jordan 2003) and Latent Semantic Analysis (Hofmann 1999). Latent Dirichlet Allocation is based on an unsupervised learning model to identify affective topics from the distribution of words. Latent Semantic Analysis (Bello-Orgaz and Jason 2016) has been extended to generate the semantic relationships based on a co-occurrence matrix. These techniques provide the mechanism for identifying patterns of affective term co-occurrence and using those patterns to identify coherent affective topics. Despite these two approaches, text mining algorithms can also be used to extract affective entities and their relationships from texts allowed for the inference of affective knowledge (J. Leskovec, A. Rajaraman, and Ullman 2014). In the algorithms, each text is represented by a vector of frequency, which indicates the number of occurrences of the particular word in the text divided by the number of words in the entire text. The vector of frequency indicates the importance of a term in a social media, such as blogs, which discusses affective opinions of new products.

\subsubsection{Ontologies}

Although web mining algorithms can be used to convert unstructured textual data from social media (Bello-Orgaz and Jason 2016), misleading information can be generated as the same word has different meaning in different contexts. For example, word 'chair' can be referred differently in different domains, as furniture and as a person:

Furniture: "A nice chair with proper back support will improve your posture" Person: "A nice chair will be mindful of agenda"

Ontologies can be used to automate human understanding and relationships of the affective concepts, and achieve a certain level of filtering accuracy (Gruber 1993). Using text mining together with domain specific ontologies can produce a better accuracy of concept identification than solely using text mining. The effectiveness of the approaches can be enhanced by including domain ontologies, semantic web technologies and machine learning, where the semantic web technologies extract the semantics of textual data in order to determine the affective domain of the textual data, and machine learning performs domain-based classification for affective design. 


\subsubsection{Data Visualisation}

As the amount of social media data is growing significantly, visualisation approaches can be used to present data in a more intuitive way for easing data understanding and providing sufficient support for decision making, in order to boost the human cognitive process (Card, Mackinlay, and Shneiderman 1999). Visualisation attempts to effectively present large datasets, quick recognition of errors and outliers in datasets, and ease hypotheses formation out of data (Ware 2012). Visualization obtains insights from unstructured temporal data using parallel rendering algorithm (Ma et al. 2003), taxonomies of interaction techniques (Yi, Kang, and Stasko 2007), and the focus context technique (Lamping, Rao, and Pirolli 1995). Visualization leads to faster user cognition, improves decision making processes and shortens commination gaps (Wright 1998). It has the potential to add value to businesses which are involved with affective design.

\subsubsection{Data Fusion}

Data Fusion is the process of integrating multiple data sources to produce more consistent, accurate, and useful information than that provided by any individual data source (Castanedo 2013). It has been applied in many fields where data is distributed and generated from diverse sources (Yaqoob et al. 2016). In affective design, to get a holistic view about products, businesses ought to integrate information from these multiple channels. In the literature, various methodologies have been proposed to accumulate heterogeneous information from diverse sources. Breur (Breur 2011) discussed data fusion as one out of four useful data analysis streams available to researchers. BelloOrgaz et al. (Bello-Orgaz, Jung, and Camacho 2016) summarized the challenges in data fusion: (i) obtaining more reliable methods for the fusing the multiple features of multimedia objects for social media applications, (ii) studying the dynamics of individual and group behaviour, (iii) characterizing the patterns of information diffusion, and (iv) identifying influential individuals in social networks.

To overcome the challenges of data fusion, different techniques in information fusion are being developed to suit real world applications and the data. These intensive techniques are derived from different computing areas including artificial intelligence, statistical estimation, pattern recognition, and so on (Yaqoob et al. 2016). However, given the very large heterogeneous dataset from social media, one of the major challenges is to identify valuable data and how to analyse them in determining useful knowledge (Bello- 
Orgaz, Jung, and Camacho 2016). Emerging Big data applications can be seen as a solution to integrate the heterogeneous and dynamic stream of data from diverse social media channels.

\subsection{Affective smart systems for affective design}

Recent research indicates that attention has been attracted to the development of affective smart systems in using the affective states of users such as emotions, facial expression and body gestures, in order to make decisions and for information provision (Katarya and Verma 2016, Balters and Steinert 2017, Bhandari et al. 2017). Affective smart systems interpret users' induced behaviour, and subsequently make decisions to cater for users' affective needs. As an example, affective tutoring systems were developed, in order to identify learner affective states and to tailor-make specified learning content to suit the learner (Kaklauskas et al. 2015). The affective tutoring system captured the learner's affective states and physiological parameters such as stress, heart rate, blood pressure, skin humidity, perspiration, temperature, and conductance. By conjoining learners' past learning data, and the newly captured affective states and physiological parameters, the affective tutoring system can personalise simpler, less stressful, more interesting and more effective learning processes.

Similar to affective tutoring systems, an affective smart system can be developed to correlate designers' initial design prototypes and the captured affective states in order to further improve customer satisfaction of new products (Zhou et al. 2014), as the consumers' affective state indicates whether one would like to purchase a product (Ahn 2010). Lu and Petiot (Lu and Petiot 2014) proposed an affective smart system to measure the emotions elicited from purchasing new products. A smart camera was developed to capture user perceptions when different perceptual design elements and engineering characteristics were used (Wang et al. 2014). The captured user perceptions were used to determine the optimal camera which satisfied both functional and affective design needs. $\mathrm{Xu}$ et al. (Xu et al. 2014) proposed to use interactive online big data to examine the realtime relationship between customers' affective satisfaction and facial expression, where the facial data was captured and analysed in real time. Their proposed framework attempted to differentiate between posed and spontaneous expressions but still cannot address all affective states other than facial expression. The effectiveness of the proposed 
framework is limited by the heterogeneity of the communication technologies and distributed topology.

\subsection{Challenges and strategies in using big data for affective design}

As discussed in the aforementioned section, machine learning is not a new domain for affective design. Big data with affective design content can be grown exponentially due to the popularity of social media and the advanced technologies of sensor networks, where the data can be included with images, speeches, videos, structural / semi-structural / unstructural data. Machine learning assists in better affective design by learning big data involving affective customer needs and product design attributes. The following challenges and strategies related to network security, parallel implementation, algorithmic development and mobile networks, are discussed in order to develop efficient machine learning technologies which offer significant learning demands including super high speed, feasible implementation and minimal human intervention.

1. Network security is important when capturing massive amounts of affective data daily from social media. It is challenging to process large volumes of data by commercial security tools which are developed for small amounts of data. For example, base-lining network object behaviour cannot be validated over a monthly period when the data size is huge (Singh 2014). Also, the correlations between disparate data sources, customer databases and live web streams, are too big to identify the buried data and perform data cleaning. It is necessary to develop effective data management toolkits to leverage big data from the streaming database systems (Condie et al. 2013).

2. Parallel implementation: Processing tons of affective data at a faster speed is challenging. Machine learning can be implemented in parallelization systems such as Hadoop and Cloud, in order to perform big data mining. Dai and Ji (Dai and Ji 2014) and He et al. (He et al. 2013) implemented Hadoop for parallel decision trees and regression; Cuzzocrea et al. (Cuzzocrea, Mumolo, and Corona 2015) developed a Cloud-based machine learning tool to predict future data. These parallelization techniques improved the efficiency and the reliability of big data mining (Wu et al. 2014) and have the potential to be implemented in machine learning for affective design involving huge amounts of affective data.

3. Algorithmic development: It is challenging to implement machine learning for the affective data involved with multichannel captures, visual images and videos, as such 
data is massive in amounts and with large dimensions. In big data mining, two technologies, feature selection and incremental learning, are generally used to tackle these challenges. Feature selection is essential to filter insignificant features which are not helpful for understanding the full data set (Olvera-López et al. 2010). Representative subsets are generated with much fewer features compared with the original number of features but they keep significant information of the original dataset. Hence the computational complexity of machine learning can be reduced. To update the machine learning parameters, incremental learning can be used on the newly captured data rather than again training with both new and old data. Incremental leaning provides an effective way for adapting algorithms on noisy (Yang and Fong 2012) and spatially big data (Wang et al. 2014).

4. Deep learning: It is challenging to digest large, comprehensive and complex text data from online sources such as web blog/forum, and social media. Although advanced technologies for information gathering and provisioning for consumers, data overload is still a problem (Workman and Riding 2016). A powerful learning mechanism is essential to comprehend the vast volumes of text data and to handle this growing deluge of online text data. IBM's Watson is a commonly used cognitive system that uses deep learning for natural language processing (High 2012). Deep neural networks have also been used for language modelling (Mikolov et al. 2013), translation (Devlin et al. 2014), document summarization (Denil et al. 2014) and opinion mining from text data (López-Sánchez, Arrieta, and Corchado 2018). Although deep neural networks have been developed for natural language processing, they only learn from word vectors appearing in the text data (Elden 2007). There is a potential problem that the same word may have a different meaning in different contexts, as machines still cannot fully understand human linguistic content such as concepts and subject behaviour. Hence, the network is likely to generate misleading analysis, which may not help in developing a product with good affective quality. To overcome this, one can integrate text mining in word vectors together with domain ontologies of affective design, where the ontologies simulate human understanding and semantic concepts of affective design (Bello-Orgaz and Jason 2016).

5. Mobile networks: Thanks to the development of 5G technology, mobile smart devices have become more and more powerful. Mobile smart devices can acquire geographical location information through positioning systems, acquire audio information through 
microphones, acquire multimedia information, acquire user gestures and other body language information through touch screens and gravity sensors (Chen, Mao, and Liu 2014). Over the years, wireless operators have improved the service level of the mobile Internet by acquiring and analyzing mobile crowd-sensing, transportation and so on (Luong et al. 2016). Mobile technology will help to tackle the challenges of developing smart affective systems which capture significant amounts of data regarding consumers' affective states and physiological parameters.

Table 4 summarizes the approaches for collecting, analysing and processing both small and large data. Also, the table summarizes the limitations and challenges of using big data and traditional survey data which is small data. It attempts to provide guidelines in using small and big data for affective design. 
Table 4: Using small data and big data for affective design

\begin{tabular}{|c|c|c|c|c|}
\hline $\begin{array}{l}\text { Data } \\
\text { sizes }\end{array}$ & Data collection methods & Data types & Data analysis and processing & Limitations or challenges \\
\hline $\begin{array}{l}\text { Small } \\
\text { data }\end{array}$ & $\begin{array}{l}\text { Questionnaires, survey, } \\
\text { interview }\end{array}$ & $\begin{array}{l}\text { Numerical data in } \\
\text { psychometric scales; } \\
\text { survey answers }\end{array}$ & $\begin{array}{l}\text { As the data is mostly the numerical data which } \\
\text { is in psychometric scales or discrete format, } \\
\text { machine learning can be directly implemented } \\
\text { to analyze the data. }\end{array}$ & $\begin{array}{l}\text { Limited numbers of perceptual design elements and Kansei } \\
\text { words can only be used in the survey questions or } \\
\text { questionnaires; } \\
\text { Expensive cost and time delay when conducting the surveys; } \\
\text { Physiological responses and sentimental expressions are } \\
\text { generally not included; } \\
\text { Consumer opinions cannot be fully covered in questionnaires or } \\
\text { consumer surveys. }\end{array}$ \\
\hline Big data & $\begin{array}{l}\text { Data source: social media such } \\
\text { as Facebook, Twitter, } \\
\text { LinkedIn, YouTube, } \\
\text { Instagram } \\
\text { Data collection technologies: } \\
\text { parallel and distributed } \\
\text { processing paradigm such as } \\
\text { MongoDB, Cassandra, } \\
\text { Hadoop (G. Bello-Orgaz \& } \\
\text { Jason, 2016) }\end{array}$ & $\begin{array}{l}\text { Social media data } \\
\text { which is mostly in text } \\
\text { format (Kaisler, } \\
\text { Armour, Espinosa, \& } \\
\text { Money, 2013) }\end{array}$ & $\begin{array}{l}\text { As the data is in text formats, the data has to be } \\
\text { transformed into numerical format before } \\
\text { analysing with machine learning; } \\
\text { Text mining (G. Bello-Orgaz \& Jason, 2016), } \\
\text { and ontologies (Gruber, 1993) are the } \\
\text { common components to transform text } \\
\text { formats into the numerical formats; } \\
\text { As data is collected from multiple data sources, } \\
\text { data fusion is applied to produce more } \\
\text { consistent data format (Castanedo, 2013); } \\
\text { Data visualization is used to present large } \\
\text { datasets in order to quickly recognize errors } \\
\text { and outliers in datasets (Ware, 2012). }\end{array}$ & $\begin{array}{l}\text { Cybernetic security: An effective data management toolkit is } \\
\text { essential to be develop to leverage big data from streaming } \\
\text { database systems (Condie, Mineiro, Polyzotis, \& Weimer, } \\
\text { 2013); } \\
\text { Large computational demand: Processing tons of affective data } \\
\text { in a faster speed is challenging. An effective parallelization } \\
\text { system has to be developed (Cuzzocrea, Mumolo, \& Corona, } \\
\text { 2015); } \\
\text { Algorithmic development: Implementation of machine learning } \\
\text { for affective data is challenging. Despite text data, big data is } \\
\text { involved with multichannel captures, which is huge in amount } \\
\text { and large dimensions (Olvera-López, Carrasco-Ochoa, } \\
\text { Martínez-Trinidad, \& Kittler, 2010); } \\
\text { Data transmission: high transmission is required as the data size } \\
\text { is huge and data dimension is large. 5G technology and } \\
\text { mobile smart devices have improved the mobile Internet in } \\
\text { acquiring mobile crowd-sensing and transportation (Luong et } \\
\text { al., 2016). }\end{array}$ \\
\hline
\end{tabular}




\section{Conclusions}

In this paper, we presented a survey of the approaches of using machine learning technologies for affective design. These technologies attempt to evaluate the relationships between affective customer needs and perceptual design elements, and to determine the optimal setting of perceptual design elements for affective design. We also discussed using machine learning technologies for discovery knowledge in customers' affective data. We also assessed the limitations and advantages of the commonly used machine learning technologies for affective data. As information for affective design can be exploited from social media which involves big data, a conceptual framework is presented to capture and analyse such big data. We also discussed the limitations and advantages of using small data and big data for affective design.

Section 2 describes the mechanisms and purposes of affective design and Kansei engineering, including how one uses Kansei Engineering to develop survey questions and questionnaires in order to study the relationships between affective customer needs and perceptual design attributes. Affective design of mobile Phones was used as a design example in survey questionnaires. Based on the survey questions in the questionnaire, small amounts of data can be collected in order to perform affective design. Section 3 presents the commonly used machine learning technologies for affective design, which were categorized to perform three tasks: affective modelling, knowledge discovery, and determination of optimal design attribute settings. For affective modelling, machine learning is used to develop a model that correlates design attributes and affective customer needs. Machine learning is used to determine optimal design attribute settings based on affective models. For knowledge discovery, machine learning is used to interpret the relationships between perceptual design elements and affective customer needs in a product. We discuss the limitations and advantages of machine learning technologies for performing affective design, thus providing guidelines for researchers who are interested to explore machine learning technologies for affective design.

As discussed at the end of Section 3, previous studies demonstrated that traditional survey data has mostly been used on machine learning for affective design. However, traditional survey data is generally time consuming and expensive to be collected and also the data cannot fully cover all affective domains of a product. Nowadays, big data 
related to affective design can be captured from social media, revealing consumer affective requirements for new products. Processing and analysing such big data effectively will become critical and widely used for affective design. We discuss the prospects and challenges in using big data to enhance affective design on which very limited research has so far been attempted. Section 4 discusses the conceptual framework and challenges of using big data for affective design. It presents the commonly used mechanisms of processing and collecting big data from the social media. As the size of the social media data is large and the data is captured from multi-sources, processing big data requires high performance computers, fast speed for data transmission and large data storage. Several strategies are suggested to tackle these challenges. We also discuss the limitations and advantages of using big data and traditional survey data which is on a much smaller scale. This will provide guideline for researchers to obtain a trade off in using big and small data for affective design.

Through this paper, an interdisciplinary collaboration between big data, machine learning and affective design is advised, as this will facilitate product designers by exploiting valuable information from big data for affective design.

\section{References:}

Ahn, H. 2010. "Modeling and analysis of affective influences on human experience, prediction, decision making, and behavior." In, edited by MIT.

Akay, D., and M. Kurt. 2009. "A neuro-fuzzy based approach to affective design." The International Journal of Advanced Manufacturing Technology 40 (5):425-437.

Aktar, D.E., A.S. Anagun, and G. Koksal. 2009. "Determination of optimal product styles by ordinal logistic regression versus conjoint analysis for kitchen faucets." International Journal of Industrial Ergonomics 39 (5):866-875.

Bahn, S., C. Lee, C.S. Nam, and M.H. Yun. 2009. "Incorporating affective customer needs for luxuriousness into product design attributes." Human Factors and Ergonomics in Manufacturing 19 (2):105-125.

Balters, S, and M Steinert. 2017. "Capturing emotion reactivity through physiology measurement as a foundation for affective engineering in engineering design science and engineering practices." Journal of Intelligent Manufacturing 28 (7):1587-1607.

Barnes, C., and S.P. Lillford. 2007. "Affective design decision-making-issues and opportunities." International Journal of CoCreation in Design and the Arts 3 (1):135-146.

Barnes, C., and S.P. Lillford. 2009. "Decision support for the design of affective products." Journal of Engineering Design 20 (5):477-492.

Barone, S., A. Lombardo, and P. Tarantino. 2009. "Analysis of User Needs for the Redesign of a Postural Seat System." Statistics for Innovation:3-25.

Bello-Orgaz, G., and J.J. Jason. 2016. "Social Big Data: Recent Achievements and New Challenges." Information Fusion 28:45-59. 
Bello-Orgaz, G., Jason J. Jung, and D. Camacho. 2016. "Social big data: Recent achievements and new challenges." Information Fusion 28:45-59.

Bhandari, U., T. Neben, K. Chang, and W.Y. Chua. 2017. "Effects of interface design factors on affective responses and quality evaluations in mobile applications." Computers in Human Behavior 72:525-534.

Blei, D.M., A.Y. Ng, and M.I. Jordan. 2003. "Latent dirichlet allocation." Journal of Machine Learning Research 3 (4-5):993-1022.

Breur, T. 2011. "Data analysis across various media: Data fusion, direct marketing, clickstream data and social media." Journal of Direct, Data and Digital Marketing Practice 13 (2):95-105. doi: 10.1057/dddmp.2011.32.

Card, S.K., J.D. Mackinlay, and B. Shneiderman. 1999. Readings in Information Visualization: Using Vision to Think: Morgan Kaufmann.

Castanedo, F. 2013. "A review of data fusion techniques." The Scientific World Journal 2013.

Chan, K.Y., K.K.F Yuen, V. Palade, and C. K. Kwong. 2014. "Computational intelligence techniques for new product development." Neurocomputing 142:1-3.

Chan, K.Y., and U. Engelke. 2017. "Varying Spread Fuzzy Regression for Affective Quality Estimation." IEEE Transactions on Fuzzy Systems 27 (3):594-613

Chan, K.Y., C.K. Kwong, and T.S. Dillon. 2012. Computational Intelligence Techniques for New Product Design. Vol. 403, Studies in Computational Intelligence: Springer.

Chan, K.Y., C.K. Kwong, T.S. Dillon, and K.Y. Fung. 2011. "An intelligent fuzzy regression approach for affective product design that captures nonlinearity and fuzziness." Journal of Engineering Design 22 (8):523-542.

Chan, K.Y., H.K. Lam, K.F.C. Yiu, and T.S. Dillon. 2017. "A flexible fuzzy regression for addressing uncertainty on aesthetic quality assessments." IEEE Transactions on Systems, Man and Cybernetics: Systems 47 (12).

Chan, K.Y., K.K.F. Yuen, V. Palade, and Y. Yue:. 2016. "Artificial intelligence techniques in product engineering." Engineering Applications of Artificial Intelligence 47:1-2.

Chang, C.C. 2008. "Factors influencing visual comfort appreciation of the product form of digital cameras." International Journal of Industrial Ergonomics 38 (1112):1007-1016.

Chen, C.H., L. Khoo, and W. Yan. 2003. "Evaluation of multicultural factors from elicited customer requirements for new product development." Research in Engineering Design 14 (3):119-130.

Chen, C.H., L.P. Khoo, and W. Yan. 2006. "An investigation into affective design using sorting technique and Kohonen self-organising map." Advances in Engineering Software 37 (5):334-349.

Chen, M., S. Mao, and Y. Liu. 2014. "Big Data: A Survey." Mobile Networks and Applications 19 (2):171-209.

Condie, T., P. Mineiro, N. Polyzotis, and M. Weimer. 2013. "Machine learning on big data." Sigmod conference.

Creusen, M. E. H., and J.P.L. Schoormans. 2005. "The different roles of product appearance in consumer choice." Journal of Product Innovation Management 22 (1):63-81.

Cuzzocrea, A., E. Mumolo, and P. Corona. 2015. "Cloud-based Machine Learning Tools for Enhanced Big Data Applications." ACM International Symposium on Cluster, Cloud and Grid Computing:908-914. 
Aktar, D.E., A.S. Anagun, and G. Koksal. 2009. "Determination of optimal product styles by ordinal logistic regression versus conjoint analysis for kitchen faucets." International Journal of Industrial Ergonomics 39 (5):866-875.

Dai, W., and W. Ji. 2014. "A MapReduce implementation of C4.5 decision tree algorithm." International Journal of Database Theory Applications 7 (1):49-60.

Deng, J.L. 1982. "Control problems of grey systems." Systems \& Control Letters 1 (5):288-294.

De Byl, P. 2015. "A conceptual affective design framework for the use of emotions in computer game design." Cyberpsychology: Journal of Psychosocial Research on Cyberspace 9 (3): article 4.

Denil, M., A. Demiraj, N. Kalchbrenner, P. Blunsom, and N. Freitas. 2014. Modelling, visualising and summarising documents with a single convolutional neural network. ArXiv: 1-10.

Devlin, J., R. Zbib, Z. Huang, T. Lamar, R. Schwartz, and J. Makhoul. 2014. "Fast and Robust Neural Network Joint Models for Statistical Machine Translation." The 52nd Annual Meeting of the Association for Computational Linguistics.

Diego-Mas, J.A., and J. Alcaide-Marzal. 2016. "Single users' affective responses models for product form design." International Journal of Industrial Ergonomics 53:102114.

Elden, L. 2007. Matrix Methods in Data Mining and Pattern Recognition: Siam.

Fan, K.K., C.H. Chiu, and C.C. Yang. 2014. "Green technology automotive shape design based on neural networks and support vector regression." Engineering Computations 31 (8):1732-1745.

Fettermann, D.C., and M.E.S. Echeveste. 2014. "New product development for mass customization: a systematic review." Production \& Manufacturing Research 2 (1):266-290.

Fung, K.Y., C.K. Kwong, K.Y Chan, and H. Jiang. 2014. "A guided search genetic algorithm using mined rules for optimal affective product design." Engineering Optimization 46 (8):1094-1108.

Fung, K.Y., C.K. Kwong, K.W.M. Siu, and K.M. Yu. 2012. "A multi-objective genetic algorithm approach to rule mining for affective product design." Expert Systems with Applications 39 (8):7411-7419.

Graner, M., and M. Missler-Behr. 2012. "The use of methods in new product development - a review of empirical literature " International Journal of Product Development $16(2): 158-184$.

Gruber, T.R. 1993. "A translation approach to portable ontology specifications." Knowledge Acquisition 5 (2):199-220.

Guo, F., W.L. Liu, F.T. Liu, H. Wang, and T.B. Wang. 2014. "Emotional design method of product presented in multi-dimensional variables based on Kansei Engineering." Journal of Engineering Design 25 (4-6):194-212.

Halavais, A. 2015. "Bigger Sociological Imaginations: Framing Big Social Data Theory and Methods." Information, Communication \& Society 15 (5):583-594.

Han, S.H., M.H. Yun, K.J. Kim, and J. Kwahk. 2000. "Evaluation of product usability: development and validation of usability dimensions and design elements based on empirical models." International Journal of Industrial Ergonomics 26 (4):477488.

He, Q., T. Shang, F. Zhuang, and Z. Shi. 2013. "Parallel extreme learning machine for regression based on MapReduce." Neurocomputing 102:52-58.

High, R. 2012. The Era of Cognitive Systems: An inside Look at Ibm Watson and How It Works.: IBM Corporation, Redbooks. 
Hofmann, T. 1999. "Probabilistic latent semantic indexing." 22nd Annual International ACM SIGIR Conference on Research and Development in Information Retrieval.

Hong, S.W., S.H. Han, and K.J. Kim. 2008. "Optimal balancing of multiple affective satisfaction dimensions: A case study on mobile phones." International Journal of Industrial Ergonomics 38 (3-4):1777-1799.

Hsiao, S.W., and H.C. Huang. 2002. "A neural network based approach for product form design." Design Studies 23 (1):67-84.

Hsiao, S.W., and M.C. Liu. 2002. "A morphing method for shape generation and image prediction in product design." Design Studies 23 (6):533-556.

Hsiao, S.W., and H.C. Tsai. 2005. "Applying a hybrid approach based on fuzzy neural network and genetic algorithm to product from design." International Journal of Industrial Ergonomics 35 (5):411-428.

Leskovec, J., A. Rajaraman, and J.D. Ullman. 2014. Mining of Massive Datasets: Cambridge University Press.

Jang, J. S. R. 1993. "ANFIS: Adaptive-network-based fuzzy inference systems." IEEE Transactions on Systems, Man and Cybernetics 23 (3):665-685.

Jang, J. S. R., and C.T. Sun. 1993. "Functional equivalence between radial basis function networks and fuzzy inference systems." IEEE Transactions on Neural Networks $4(1): 156-159$.

Jiang, H., C.K. Kwong, Y. Liu, and W.H. Ip. 2015. "A methodology of integrating affective design with defining engineering specifications for product design." International Journal of Production Research 53 (8):2472-2488.

Jiang, H., C.K. Kwong, W.Y. Park, and K.M. Yu. 2018. "A multi-objective PSO approach of mining association rules for affective design based on online customer reviews." Journal of Engineering Design.

Jiang, H., C.K. Kwong, K.W. Siu, and Y. Liu. 2015. "Rough set and PSO-based ANFIS approaches to modeling customer satisfaction for affective product design." Advanced Engineering Informatics 29 (3):727-738.

Jiao, J., Y. Zhang, and M. Helander. 2006. "A Kansei mining system for affective design." Expert Systems with Applications 30 (4):658-673.

Jiao, J., Y. Zhang, and Y. Wang. 2007. "A heuristic genetic algorithm for product portfolio planning." Computers \& Operations Research 34 (6):1777-1799.

Jiao, J.Q., Q. Xu, J. Du, Y. Zhang, M. Helander, and H.M. Khalid. 2008. "Analytical affective design with ambient intelligence for mass customization and personalization." International Journal of Flexible Manufacturing Systems 19 (4):570-595.

Jin, J., Y. Liu, P Ji, and H. Liu. 2016. "Understanding big consumer opinion data for market-driven product design." International Journal of Production Research 54 (10):3019-3041.

Kaisler, S., F. Armour, J.A. Espinosa, and W. Money. 2013. "Big Data: Issues and Challenges Moving Forward." Hawaii International Conference on System Sciences.

Kaklauskas, A., A. Kuzminske, E.K. Zavadskas, A. Daniunas, G. Kaklauskas, M. Seniut, J. Raistenskis, A. Safonov, R. Kliukas, A. Juozapaitis, A. Radzeviciene, and R. Cerkauskiene. 2015. "Affective Tutoring System for Built Environment Management." Computers \& Education 82:202-216.

Katarya, R., and O.P. Verma. 2016. "Recent developments in affective recommender systems." Physica A 461:182-190.

Kongprasert, N., D. Brissaud, C. Bouchard, A. Aoussat, and S. Butdee. 2008. "How to design and process brand identity through an integrated innovative approach." 
Proceedings, IEEE International Conference on Industrial Engineering and Engineering Management.

Kuang, J., and P. Jiang. 2008. "Product platform design for a product family based on Kansei engineering." Journal of Engineering Design 20 (6):589-607.

Kurosu, M., and K. Kashimura. 1995. "Apparent usability vs. inherent usability: experimental analysis on the determinants of the apparent usability." Proceedings of the Conference Companion on Human Factors in Computing Systems.

Kusiak, A., and F.A. Salustri. 2007. "Computational intelligence in product design engineering: review and trends." IEEE Transactions on Systems, Man and Cybernetics - Part C: Applications and Reviews 37 (5):766-778.

Kwong, C.K., Y. Chen, K.Y. Chan, and X. Luo. 2010. "A generalised fuzzy least-squares regression approach to modelling relationships in QFD." Journal of Engineering Design 21 (5):601-613.

Kwong, C.K., K.Y. Fung, H. Jiang, K.Y. Chan, and K.W.M. Siu. 2013. "A modified dynamic evolving neural-fuzzy approach to modeling customer satisfaction for affective design." The Scientific World Journal.

Kwong, C.K., H. Jiang, and X.G. Luo. 2016. "AI-based methodology of integrating affective design, engineering, and marketing for defining design specifications of new products." Engineering Applications of Artificial Intelligence 1.

Kwong, C.K., T.C. Wong, and K.Y. Chan. 2009. "A methodology of generating customer satisfaction models for new product development using a neuro-fuzzy approach." Expert Systems with Applications 36 (8):11262-11270.

Lai, H.H., Y.M. Chang, and H.C. Chang. 2005. "A robust design approach for enhancing the feeling quality of a product: a car profile case study." International Journal of Industrial Ergonomics 35 (5):445-460.

Lai, H.H., Y.C. Lin, and C.H. Yeh. 2005. "Form design of product image using grey relational analysis and neural network models." Computers \& Operations Research 32 (10):2689-2711.

Lai, H.H., Y.C. Lin, C.H. Yeh, and C.H. Wei. 2006. "User-oriented design for the optimal combination on product design." International Journal of Production Economics 100 (2):253-267.

Lamping, J., R. Rao, and P. Pirolli. 1995. "A Focus+ Context Technique Based on Hyperbolic Geometry for Visualizing Large Hierarchies." SIGCHI Conference on Human Factors in Computing Systems.

Lanzotti, A., and P. Tarantino. 2008. "Kansei engineering approach for total quality design and continuous innovation." The TQM Journal 20 (4):324-337.

Lin, Y.C., H.H. Lai, and C.H. Yeh. 2007. "Consumer-oriented product form design based on fuzzy logic: A case study of mobile phones." International Journal of Industrial Ergonomics 37 (6):531-543.

Lin, Y.C., and C.C. Wei. 2016. "A hybrid consumer-oriented model for product affective design: An aspect of visual ergonomics." Human factors and ergonomics in manufacturing 27 (1):17-29.

Lin, Y.C., C.H. Yeh, and C.H. Hung. 2008. "A Neural Network Approach to the Optimal Combination of Product Color Design." Proceedings, Fourth International Conference on Networked Computing and Advanced Information Management.

Ling, S.H., P.P. San, K.Y. Chan, F.H.F. Leung, and Y. Liu. 2014. "An intelligent swarm based-wavelet neural network for affective mobile phone design." Neurocomputing 142:30-38. 
López-Sánchez, D., A.G. Arrieta, and J.M. Corchado. 2018. "Neural networks and transfer learning applied to multimedia web mining." 14th International Conference on Distributed Computing and Artificial Intelligence.

Lu, W., and J.F. Petiot. 2014. "Affective design of products using an audio-based protocol: application to eyeglass frame." International Journal of Industrial Ergonomics 44:383-394.

Luong, N.C., D.T. Hoang, P. Wang, D. Niyato, D.I. Kim, and Z. Han. 2016. "Data Collection and Wireless Communication in Internet of Things (IoT) Using Economic Analysis and Pricing Models: A Survey." IEEE Communications Surveys and Tutorials 18 (4):2546-2590.

Ma, K.L., A. Stompel, J. Bielak, O. Ghattas, and E.J. Kim. 2003. "Visualizing Very Large-Scale Earthquake Simulations." ACM/IEEE Conference in Supercomputing.

McDonagh, D., A. Bruseberg, and C. Haslam. 2002. "Visual product evaluation: exploring users' emotional relationships with products." Applied Ergonomics 33:231-240.

Mikolov, T., I. Sutskever, K. Chen, G.S. Corrado, and J. Dean. 2013. "Distributed Representations of Words and Phrases and Their Compositionality." In Advances in Neural Information Processing Systems, 3111-3119. The MIT Press.

Mitchell, T.M. 1997. Machine Learning: McGraw-Hill Science/Engineering/Math.

Nagamachi, M. 1995. "Kansei Engineering: A new ergonomic consumer-oriented technology for product development." International Journal of Industrial Ergonomics 15 (1):3-11.

Nagamachi, M. 2010. Kansei/Affective Engineering: CRC Press.

Nishino, T., M. Nagamachi, and H. Tanaka. 2006. "Variable precision bayesian rough set model and its application to kansei engineering." Lecture Notes in Computer Science (4100):190-206.

Noble, C.H., and M. Kumar. 2008. "Using product design strategically to create deeper consumer connections." Business Horizons 51 (5):441-450.

Norman, D. 2004. Emotional Design: why We Love or Hate Everyday Things. New York: Basic Books.

Okamoto, R.H., T. Nishino, and M. Nagamachi. 2007. "Comparison between statistical and lower/upper approximations rough sets models for beer can design and prototype evaluation." 10th International Conference on Quality Management and Organizational Development.

Olvera-López, J.A., J.A. Carrasco-Ochoa, J.F. Martínez-Trinidad, and J. Kittler. 2010. "A review of instance selection methods." Artificial Intelligence Review 34 (2):133-143.

Oztekin, A., A. Iseri, S. Zaim, and A. Nikov. 2013. "A Taguchi-based Kansei engineering study of mobile phones at product design stage." Production Planning \& Control 24 (6):465-474.

Park, J., and S.H. Han. 2004. "A fuzzy rule-based approach to modeling affective user satisfaction towards office chair design." International Journal of Industrial Ergonomics 4 (1):31-47.

Rawlings, J. O. 1988. Applied Regression Analysis: A Research Tool: Monterey, CA, USA: Wadsworth and Brooks.

Rich, E., K. Knight, and S.B. Nair. 2009. Artificial Intelligence: McGraw Hill.

Kim, S.H., and Y.J. Lee. 2016. "The User Experience of Smart-Phone Information Hierarchy and Screen Transition Patterns." International Journal of Multimedia and Ubiquitous Engineering 11 (4):293-302. 
Saridakis, K.M., and A.J. Dentsoras. 2008a. "Soft computing in engineering design - A review." Advanced Engineering Informatics 22 (2):202-221.

Saridakis, K.M., and A.J. Dentsoras. 2008b. "Soft computing in engineering design - A review." Advanced Engineering Informatics 22 (2):202-221.

Sekkeli, G., G. Koksal, I. Batmaz, and O.T. Bayrak. 2010. "Classification models based on Tanaka's fuzzy linear regression approach: The case of customer satisfaction modeling." Journal of Intelligent \& Fuzzy systems 21 (5):341-351.

Shen, H.C., and K.C. Wang. 2016. "Affective product form design using fuzzy Kansei engineering and creativity." Journal of Ambient Intelligence and Humanized Computing 7 (6):875-888.

Shi, F., S. Sun, and J. Xu. 2012. "Employing rough sets and association rule mining in KANSEI knowledge extraction." Information Sciences 196:118-128.

Shi, L., S. Olafsson, and Q. Chen. 2001. "An optimization framework for product design." Management Science 47 (12):1681-1692.

Shieh, M.D., and F.C. Hsu. 2013. "A consensus prediction model of affective responses in Kansei engineering system " International Journal of Digital Content Technology and its Applications 7 (64):555-562.

Shieh, M.D., Y. Li, and C.C. Yang. 2018. "Comparison of multi-objective evolutionary algorithms in hybrid Kansei engineering system for product form design." Advanced Engineering Informatics 36:31-42.

Shieh, M.D., and C.C. Yang. 2008. "Classification model for product form design using fuzzy support vector machines." Computer \& Industrial Engineering 55 (1):150164.

Shieh, M.D., Y.E. Yeh, and C.L. Huang. 2016. "Eliciting design knowledge from affective responses using rough sets and Kansei engineering system." Journal of Ambient Intelligence and Humanized Computing 7 (1).

Shimizu, Y., and Y. Jindo. 1995. "A fuzzy logic analysis method for evaluation human sensitivities." International Journal of Industrial Ergonomics 15:39-47.

Simpson, T.W. 2004. "Product platform design and customization: status and promise." Artificial Intelligence for Engineering Design, Analysis and Manufacturing 18 (1):3-20.

Singh, J. 2014. "Real time BIG data analytic: Security concern and challenges with Machine Learning algorithm." Conference on IT in Business, Industry and Government.

Smith, G.C., and S. Smith. 2012. "Latent semantic engineering - a new conceptual usercentered design approach." Advanced Engineering Informative 26:456-473.

Song, I., and G. Guido. 2006. "Affective web service design." Pacific Rim International Conference on Artificial Intelligence.

Song, I., and V. John. 2013. "Affective Core-Banking Services for Microfinance." In Studies in Computational Intelligence, 91-102. Springer. Original edition, Springer.

StorageServers. 2016. "How much data is created daily?". https://storageservers.wordpress.com/2016/02/06/how-much-data-is-createddaily/.

Sun, J., D.K. Kalenchuk, D. Xue, and P. Gu. 2000. "Design candidate identification using neural network-based fuzzy reasoning." Robotics and Computer-Integrated Manufacturing 16 (5):383-396.

Syutono, S.B., S.H. Abdul-Rashid, H. Aoyama, and Z. Taha. 2016. "Fuzzy-based Taguchi method for multi-response optimization of product form design in Kansei 
engineering: a case study on car form design." Journal of Advanced Mechanical Design, Systems, and Manufacturing 10 (9):Paper No.16-00363.

Tanaka, H., S. Uejima, and K. Asai. 1982. "Linear regression analysis with fuzzy model." IEEE Transactions on Systems, Man and Cybernetics 12:903-907.

Tanoue, C., K. Ishizaka, and M. Nagamachi. 1997. "Kansei engineering: a study on perception of vehicle interior image." International Journal of Industrial Ergonomics 19 (2):115-128.

Tsai, H.C., S.W. Hsiao, and F.K. Hung. 2006. "An image evaluation approach for parameter-based product form and color design." Computer-Aided Design 38 (2):157-171.

Wang, C. 2018. "Combining rough set theory with fuzzy cognitive pairwise rating to construct a product platform for tablet design and recommendation." Journal of Engineering Design.

Wang, C.H. 2015. "ntegrating Kansei engineering with conjoint analysis to fulfil market segmentation and product customisation for digital cameras." International journal of production research 53 (8):2427-2438.

Wang, C.H., and H.T. Chin. 2016. "Integrating affective features with engineering features to seek the optimal product varieties with respect to the niche segments." Advanced Engineering Informative.

Wang, K.C. 2011. "A hybrid Kansei engineering design expert system based on grey system theory and support vector regression." Expert Systems with Applications 38:8738-8750.

Wang, K.C., and F.R. Ju. 2013. "An innovative design methodology KKBDCA for affective product development." Mathematical Problems in Engineering 2013:Article ID 629708.

Wang, L., L. Ke, P. Liu, R. Ranjan, and L. Chen. 2014. "IK-SVD: dictionary learning for spatial big data via incremental atom update." Computing in Science and Engineering:41-52.

Ware, C. 2012. Information Visualization: Perception for Design: Elsevier.

Workman, M., and D. Riding. 2016. "Semantic Cognition and the Ontological to Epistemic Transformation: Using Technologies to Facilitate Understanding." In Semantic Web, edited by M. Workman and D. Riding, 7-30. Springer.

Wright, W. 1998. "Business Visualization Adds Value." IEEE Computer Graphics and Applications 18 (4):39.

Wu, X., X. Zhu, G.-Q. Wu, and W. Ding. 2014. "Data Mining with Big Data." IEEE Transactions on Knowledge and Data Engineering 26 (1):97-107.

$\mathrm{Xu}$, Y., Z. Musgrave, B. Noble, and M. Bailey. 2014. "Workload-Aware Provisioning in Public Clouds." IEEE Internet Computing 18 (4):15-21.

Yadav, C., J. Rajeev, A.R Singh, and P.K. Mishra. 2016. "Kano integrated robust design approach for aesthetical product design: a case study of a car profile." Journal of Intelligent manufacturing:1-19.

Yanagisawa, H., and S. Fukuda. 2005. "Interactive reduct evolutional computation for aesthetic design." Journal of Computing and Information Science in Engineering $5(1): 1-7$.

Yang, C. C. 2011a. "Constructing a hybrid Kansei engineering system based on multiple affective responses: Application to product form design." Computers \& Industrial Engineering 60 (4):760-768.

Yang, C.C. 2011b. "A classification-based Kansei engineering system for modeling consumers' affective responses and analyzing product form features." Expert Systems with Applications 38:11382-11393. 
Yang, C.C., and M.D. Shieh. 2010. "A support vector regression based prediction model of affective responses for product form design." Computers \& Industrial Engineering 59 (4):682-689.

Yang, H., and S. Fong. 2012. "Incrementally optimized decision tree for noisy big data." 1st International Workshop on Big Data, Streams and Heterogeneous Source Mining: Algorithms, Systems, Programming Models and Applications.

Yaqoob, I., V. Chang, A. Gani, S. Mokhtar, I.A.T. Hashem, E. Ahmed, N.B. Anuar, and S.U. Khan. 2016. "Information fusion in social big data: Foundations, state-ofthe-art, applications, challenges, and future research directions." International Journal of Information Management.

Yi, J.S., Y.A. Kang, and J. Stasko. 2007. "Toward a Deeper Understanding of the Role of Interaction in Information Visualization." IEEE Transactions on Visualization and Computer Graphics 13 (6):1224-1231.

Zhai, L.Y., L.P. Khoo, and Z.W. Zhong. 2009a. "A dominance-based rough set approach to Kansei Engineering in product development." Expert Systems with Applications 36 (1):393-402.

Zhai, L.Y., L.P. Khoo, and Z.W. Zhong. 2009b. "A rough set based decision support approach to improving consumer affective satisfaction in product design." International Journal of Industrial Ergonomics 39:295-302.

Zhang, P., and N. Li. 2005. "The importance of Affective Quality." Communications of the ACM 48 (9):105-108.

Zhou, F., J.R. Jiao, D. Schaefer, and S. Chen. 2009. "Rough set based rule mining for affective design." Proceedings, International Conference on Engineering Design, Stanford University, Stanford, CA, USA.

Zhou, F., B. Lei, Y. Liu, and R.J. Jiao. 2017. "Affective parameter shaping in user experience prospect evaluation based on hierarchical Bayesian estimation." Expert Systems with Applications 78:1-15.

Zhou, F., X. Qu, J.R. Jiao, and M.G. Helander. 2014. "Emotion prediction from physiological signals: A comparison study between visual and auditory elicitors." Interacting with Computers 26:285-302. 